\title{
Diurnal, seasonal and long-term variations of global formaldehyde columns inferred from combined OMI and GOME-2 observations
}

\author{
I. De Smedt ${ }^{1}$, T. Stavrakou ${ }^{1}$, F. Hendrick ${ }^{1}$, T. Danckaert ${ }^{1}$, T. Vlemmix ${ }^{1}$, G. Pinardi ${ }^{1}$, N. Theys ${ }^{1}$, C. Lerot $^{1}$, C. Gielen ${ }^{1}$, \\ C. Vigouroux ${ }^{1}$, C. Hermans ${ }^{1}$, C. Fayt ${ }^{1}$, P. Veefkind ${ }^{2}$, J.-F. Müller ${ }^{1}$, and M. Van Roozendael ${ }^{1}$ \\ ${ }^{1}$ Belgian Institute for Space Aeronomy (BIRA-IASB), Brussels, Belgium \\ ${ }^{2}$ Royal Netherlands Meteorological Institute (KNMI), De Bilt, the Netherlands
}

Correspondence to: I. De Smedt (isabelle.desmedt@aeronomie.be)

Received: 26 February 2015 - Published in Atmos. Chem. Phys. Discuss.: 23 April 2015

Revised: 21 October 2015 - Accepted: 23 October 2015 - Published: 10 November 2015

\begin{abstract}
We present the new version (v14) of the BIRAIASB algorithm for the retrieval of formaldehyde $\left(\mathrm{H}_{2} \mathrm{CO}\right)$ columns from spaceborne UV-visible sensors. Applied to OMI measurements from Aura and to GOME-2 measurements from MetOp-A and MetOp-B, this algorithm is used to produce global distributions of $\mathrm{H}_{2} \mathrm{CO}$ representative of midmorning and early afternoon conditions. Its main features include (1) a new iterative DOAS scheme involving three fitting intervals to better account for the $\mathrm{O}_{2}-\mathrm{O}_{2}$ absorption, (2) the use of earthshine radiances averaged in the equatorial Pacific as reference spectra, and (3) a destriping correction and background normalisation resolved in the across-swath position. For the air mass factor calculation, a priori vertical profiles calculated by the IMAGES chemistry transport model at 09:30 and 13:30 LT are used. Although the resulting GOME-2 and OMI $\mathrm{H}_{2} \mathrm{CO}$ vertical columns are found to be highly correlated, some systematic differences are observed. Afternoon columns are generally larger than morning ones, especially in mid-latitude regions. In contrast, over tropical rainforests, morning $\mathrm{H}_{2} \mathrm{CO}$ columns significantly exceed those observed in the afternoon. These differences are discussed in terms of the $\mathrm{H}_{2} \mathrm{CO}$ column variation between mid-morning and early afternoon, using ground-based MAX-DOAS measurements available from seven stations in Europe, China and Africa. Validation results confirm the capacity of the combined satellite measurements to resolve diurnal variations in $\mathrm{H}_{2} \mathrm{CO}$ columns. Furthermore, vertical profiles derived from MAX-DOAS measurements in the Beijing area and in Bujumbura are used for a more detailed validation exercise. In both regions, we find an agreement better than $15 \%$ when MAX-DOAS profiles are used as a priori for the
\end{abstract}

satellite retrievals. Finally, regional trends in $\mathrm{H}_{2} \mathrm{CO}$ columns are estimated for the 2004-2014 period using SCIAMACHY and GOME-2 data for morning conditions, and OMI for early afternoon conditions. Consistent features are observed, such as an increase of the columns in India and central-eastern China, and a decrease in the eastern US and Europe. We find that the higher horizontal resolution of OMI combined with a better sampling and a more favourable illumination at midday allow for more significant trend estimates, especially over Europe and North America. Importantly, in some parts of the Amazonian forest, we observe with both time series a significant downward trend in $\mathrm{H}_{2} \mathrm{CO}$ columns, spatially correlated with areas affected by deforestation.

\section{Introduction}

Atmospheric formaldehyde $\left(\mathrm{H}_{2} \mathrm{CO}\right)$ is an intermediate product common to the degradation of many volatile organic compounds (VOCs). While the global formaldehyde background is due to methane oxidation, emissions of nonmethane volatile organic compounds (NMVOCs) from biogenic, biomass burning and anthropogenic continental sources result in important and localised production of $\mathrm{H}_{2} \mathrm{CO}$. The global sink of $\mathrm{H}_{2} \mathrm{CO}$ is due to photolysis and oxidation by $\mathrm{OH}$, resulting in a photochemical lifetime of only a few hours. Elevated concentrations of $\mathrm{H}_{2} \mathrm{CO}$ can therefore be related to the emission of reactive NMVOCs. Monitoring the spatial and temporal variability of NMVOC emissions is essential for a better understanding of the processes that not only control the production and the evolution of 
tropospheric ozone, a key actor in air quality and climate change, but also of the hydroxyl radical $\mathrm{OH}$ and secondary organic aerosols. For these reasons, $\mathrm{H}_{2} \mathrm{CO}$ satellite observations have been increasingly used in combination with tropospheric chemistry transport models to constrain NMVOC emissions (i.a. Palmer et al., 2006; Fu et al., 2007; Millet et al., 2008; Stavrakou et al., 2009a, b; 2014; Curci et al., 2010; Barkley et al., 2013; Fortems-Cheiney et al., 2012; Marais et al., 2012, Zhu et al., 2014).

For more than 15 years, mid-morning formaldehyde tropospheric columns have been retrieved from the successive nadir-scanning spectrometers GOME on ERS-2 (19962003) (Chance et al., 2000; Palmer et al., 2001; De Smedt et al., 2008), SCIAMACHY on ENVISAT (2002-2011) (Wittrock et al., 2006; De Smedt et al., 2008) and GOME-2 on MetOp-A and MetOp-B (2006- and 2012-) (De Smedt et al., 2012; Hewson et al., 2013). Since 2004, complementary early afternoon $\mathrm{H}_{2} \mathrm{CO}$ columns have also been available from the OMI imaging spectrometer on Aura (Kurosu, 2008; Millet et al., 2008; González Abad et al., 2015a), and since 2011 from OMPS on SUOMI-NPP (Li et al., 2015; González Abad et al., 2015b). In addition to formaldehyde, glyoxal - another short-lived NMVOC - has also successfully been retrieved from SCIAMACHY (Wittrock et al., 2006), GOME-2 (Vrekoussis et al., 2010; Lerot et al., 2010) and OMI (Alvarado et al., 2014; Chan Miller et al., 2014).

From 2017 onward, the morning observations will be continued with a third GOME-2 instrument to be launched on MetOp-C (Callies et al., 2000), while the afternoon observations will be extended with the TROPOMI instrument (Veefkind et al., 2012), to be launched in 2016 as part of the Copernicus Sentinel 5 Precursor (S-5P) mission, and later with the Sentinel-5 mission to be operated on the MetOp Second Generation platform (Ingmann et al., 2012). Also at the 2020 horizon, the Sentinel-4 instrument on the geostationary Meteosat Third Generation (MTG) platform will allow for hourly observations of $\mathrm{H}_{2} \mathrm{CO}$ over Europe, while TEMPO (NASA) and GEMS (KARI) will provide geostationary measurements for North America and Asia respectively. To realise the full potential of these missions, it is crucial to develop high-quality and consistent retrieval algorithms applicable to the different satellite sensors, taking into account their differences in horizontal resolution and sampling. Likewise, it is essential to understand the diurnal variations of the sources and sinks of formaldehyde, in order to exploit the synergy between the morning and afternoon satellite observations. To our knowledge, so far, the use of combined morning and afternoon $\mathrm{H}_{2} \mathrm{CO}$ satellite observations has only been reported over Amazonia, using SCIAMACHY and OMI measurements (Barkley et al., 2011, 2013).

Ground-based measurements are essential to quantitatively assess the seasonal and diurnal variations of the tropospheric $\mathrm{H}_{2} \mathrm{CO}$ columns. However, up to now, very few validation studies have been reported for satellite $\mathrm{H}_{2} \mathrm{CO}$ observations (Wittrock et al., 2006; Vigouroux et al., 2009) because of the general lack of suitable ground-based measurements, in particular for tropical regions where $\mathrm{H}_{2} \mathrm{CO}$ columns are among the highest worldwide (Stavrakou et al., 2009b; Marais et al., 2012; Barkley et al., 2013). Also, very little attention has been paid to the diurnal variations of the $\mathrm{H}_{2} \mathrm{CO}$ columns and to their local dependencies, which are a complex blend of local NMVOC emission variations, $\mathrm{H}_{2} \mathrm{CO}$ production and loss via oxidation and photolysis depending on local chemical regimes and season. In this regard, the latest generation of MAX-DOAS instruments and retrieval algorithms offer new perspectives for the validation of tropospheric trace gas concentrations and aerosol optical densities (Clémer et al., 2010; Pinardi et al., 2013; Vlemmix et al., 2014; Wang et al., 2014).

This study focuses on tropospheric formaldehyde retrievals from OMI, using an algorithm historically developed within the TEMIS (Tropospheric Emission Monitoring Internet Service) framework and applied to morning observations from the GOME, SCIAMACHY and GOME-2 sensors (http://h2co.aeronomy.be). We present several adaptations that have been implemented to handle observations from the OMI imaging spectrometer, as well as a number of more general improvements to the algorithm, giving rise to a new version of the BIRA-IASB $\mathrm{H}_{2} \mathrm{CO}$ retrieval algorithm (version 14). This version has been applied to the complete time series of OMI measurements, as well as to the GOME-2 measurements from MetOp-A and MetOp-B platforms. For the first time, differences between morning and afternoon $\mathrm{H}_{2} \mathrm{CO}$ columns are estimated at the global scale and discussed in terms of $\mathrm{H}_{2} \mathrm{CO}$ diurnal variations, horizontal resolution effects and retrieval uncertainties. Moreover, ground-based measurements at seven stations, covering midlatitude and tropical locations, are used to validate the observed $\mathrm{H}_{2} \mathrm{CO}$ columns and their diurnal changes as derived from the combined satellite data sets.

The paper is structured as follows: Sect. 2 introduces the main characteristics of the OMI and GOME-2 instruments. Section 3 describes the new version (v14) of the $\mathrm{H}_{2} \mathrm{CO}$ retrieval algorithm. The $\mathrm{H}_{2} \mathrm{CO}$ tropospheric columns obtained from GOME-2 and OMI measurements are presented and compared in Sect. 4, and the main results of our validation studies are outlined in Sect. 5. Finally, the long-term variations of the $\mathrm{H}_{2} \mathrm{CO}$ columns over the last decade are discussed in Sect. 6.

\section{Satellite instruments}

\subsection{OMI on Aura}

The Aura satellite was launched in July 2004, in a Sun-synchronous polar orbit crossing the Equator around 13:30 LT (in ascending mode). It is the third major component of the NASA Earth Observing System (EOS) following Terra (launched 1999) and Aqua (launched 2002). OMI 
(Ozone Monitoring Instrument) is a nadir-viewing imaging spectrometer that measures the solar radiation backscattered by the Earth's atmosphere and surface over the wavelength range from 270 to $500 \mathrm{~nm}$ with a spectral resolution of about $0.5 \mathrm{~nm}$ (Levelt et al., 2006). The light entering the telescope is depolarised using a scrambler and then split into two channels: a UV channel (wavelength range $270-380 \mathrm{~nm}$ ) and a VIS (visible) channel (wavelength range $350-500 \mathrm{~nm}$ ). The $114^{\circ}$ viewing angle of the telescope corresponds to a $2600 \mathrm{~km}$ wide swath on the Earth's surface, which enables nearly daily global coverage. In the nominal global operation mode, the OMI ground pixel size varies from $13 \times 24 \mathrm{~km}^{2}$ at nadir to $28 \times 150 \mathrm{~km}^{2}$ at the edges of the swath. For this work, we have used the OMI Level 1B UV Global Radiances Data Product (OML1BRUG - version 003) provided on the NASA website (http://disc.sci.gsfc.nasa.gov/ Aura/data-holdings/OMI/oml1brug_v003.shtml).

\subsection{GOME-2 on MetOp-A and MetOp-B}

The MetOp-A and MetOp-B satellites were respectively launched in October 2006 and September 2012, in Sunsynchronous polar orbits with Equator-crossing times of 09:30 and 09:00 LT (in descending node). Both satellites carry the same types of GOME-2 (Global Ozone Monitoring Experiment) instruments. Hereinafter, we will refer to them as GOME-2A and GOME-2B (or G2A and G2B). GOME-2 (Callies et al., 2000; Munro et al., 2006) is an improved version of the GOME instrument which flew on the ERS-2 satellite. It is a nadir-viewing scanning spectrometer with four main optical channels, covering the spectral range between 240 and $790 \mathrm{~nm}$ with a spectral resolution between 0.26 and $0.51 \mathrm{~nm}$. Additionally, two polarisation components are measured with polarisation measurement devices (PMDs) at 30 broad-band channels covering the full spectral range. A direct Sun spectrum is also measured via a diffuser plate once per day. The default swath width of the GOME-2 scan is $1920 \mathrm{~km}$, allowing for global Earth coverage within $1.5-3$ days at the Equator. The nominal ground pixel size is $80 \times 40 \mathrm{~km}^{2}$. For this work, we have used the EUMETSAT GOME-2A and GOME-2B level 1B data version 5.3.0 from the beginning of their time series up to mid-June 2014, and version 6.0.0 afterwards.

\section{Formaldehyde retrievals}

We use a DOAS (differential optical absorption spectroscopy) algorithm, including three main steps, further detailed in Sects. 3.1, 3.2 and 3.3: (1) the fit of absorption cross-section databases to the log ratio of measured Earth reflectance to retrieve $\mathrm{H}_{2} \mathrm{CO}$ slant columns $\left(N_{\mathrm{s}}\right)$, (2) a background normalisation procedure to eliminate remaining unphysical dependencies, and (3) the calculation of tropospheric air mass $(M)$ factors using radiative transfer calcula- tions and modelled a priori profiles. The tropospheric $\mathrm{H}_{2} \mathrm{CO}$ vertical column $\left(N_{\mathrm{v}}\right)$ is related to intermediate quantities by the equation

$N_{\mathrm{v}}=\frac{\Delta N_{\mathrm{s}}}{M}+N_{\mathrm{v}, 0, \text { CTM }}$,

where $\Delta N_{\mathrm{s}}$ is the background-corrected slant column density, and $N_{\mathrm{v}, 0, \text { CTM }}$ is the model background column in the reference sector. More detailed equations can be found in our previous publications (e.g. De Smedt et al., 2011, 2014).

Level-2 formaldehyde products developed at BIRA-IASB are provided via the TEMIS website. The algorithms used to generate these products are designed to be as consistent as possible, in order to optimise the overall coherency of the resulting time series. Over the years, scientific developments have led to step-by-step improvements in the quality of the data products. This entails regular reprocessing of the data sets. The retrieval settings presented here for the GOME-2 and OMI measurements are based on the BIRA algorithm developed for GOME-2 (De Smedt et al., 2012), but also include a number of adaptations allowing for the efficient processing of imaging instruments and additional improvements as further detailed in this section. The main differences compared to version 12 are (1) the use of daily radiances as DOAS reference spectra, (2) the inclusion of $\mathrm{O}_{2}-\mathrm{O}_{2}$ in the $\mathrm{BrO}$ and $\mathrm{H}_{2} \mathrm{CO}$ retrieval intervals, and (3) the pre-fit of $\mathrm{O}_{2}-$ $\mathrm{O}_{2}$ in a dedicated retrieval interval. For the reference sector correction, which so far has been resolved in latitude and time, an additional dimension (viewing zenith angle or detector row) is now introduced as a destriping procedure. An updated version of the IMAGES model a priori profiles is sampled at the respective satellite overpass times. Quality flags have been defined, in order to better select the valid satellite observations. Finally, the format of the level-2 data files has been changed to HDF-5. As for the previous algorithm versions, level-2 and level-3 data products of version 14 are openly available on TEMIS (http://h2co.aeronomie.be). Comparisons between the BIRA-IASB OMI $\mathrm{H}_{2} \mathrm{CO}$ product and the OMI operational product from $\mathrm{SAO}$ can be found in González Abad et al. (2015b), while comparisons with the NASA OMPS PCA product can be found in Li et al. (2015).

\subsection{Slant columns}

The formaldehyde slant columns are retrieved in the interval 328.5-346 nm. Retrieval settings are summarised in Table 1. We use the QDOAS software developed at BIRA-IASB for the DOAS retrieval of trace gases from many common satellite and ground-based instruments. QDOAS is distributed under the GNU GPL license version 2.0 (Danckaert et al., 2014, http://uv-vis.aeronomie.be/software/QDOAS).

In QDOAS, the wavelength registration of the reference spectrum is fine-tuned by means of a calibration procedure making use of the solar Fraunhofer lines. To this end, a highly accurate reference solar atlas (Chance and Kurucz, 

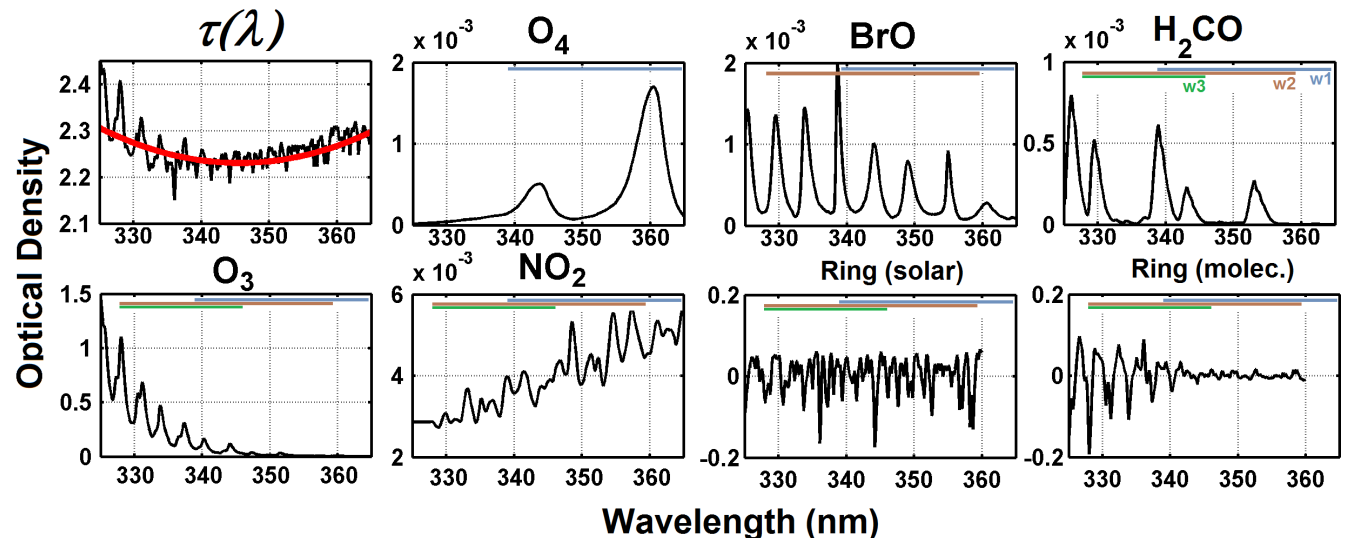

Figure 1. Typical log ratio of the measured Earth reflectance and fitted low-order polynomial (black and red lines in the first panel), and optical densities of $\mathrm{O}_{2}-\mathrm{O}_{2}\left(\mathrm{O}_{4}\right), \mathrm{BrO}, \mathrm{H}_{2} \mathrm{CO}, \mathrm{O}_{3}, \mathrm{NO}_{2}$ and the Ring effect (solar lines and molecular) in the near UV. The slant columns have been taken as $0.4 \times 10^{42}$ molec $^{2} \mathrm{~cm}^{-5}$ for $\mathrm{O}_{4}, 10^{14}$ molec cm ${ }^{-2}$ for $\mathrm{BrO}, 10^{16} \mathrm{molec} \mathrm{cm}^{-2}$ for $\mathrm{H}_{2} \mathrm{CO}_{1} 10^{20} \mathrm{molec}^{-2}$ for $\mathrm{O}_{3}$ and $1 \times 10^{16}$ molec $\mathrm{cm}^{-2}$ for $\mathrm{NO}_{2}$. The different wavelength intervals used in the retrieval are indicated as w1, w2 and w3.

2010) is degraded at the resolution of the instrument, through convolution by the instrumental slit function. The absorption cross sections of the different trace gases are also convolved with the instrumental slit function. In the case of GOME-2, the slit function shape is fitted during the calibration procedure, in order to take into account its changes with time (Dikty and Richter, 2011; De Smedt et al., 2012). In the case of OMI, pre-flight measured slit functions (Dobber et al., 2006) are used, and the calibration is performed for each binned spectrum of the detector array (60 rows). Except for the reported row anomaly that has dynamically evolved over the years (http://www.knmi.nl/omi/research/ product/rowanomaly-background.php), the performance of the OMI instrument has proven to be very stable in time (Dobber et al., 2008). In contrast to previous work, we now moved to the systematic use of daily radiance spectra averaged in the equatorial Pacific $\left(15^{\circ} \mathrm{S}-15^{\circ} \mathrm{N}, 180-240^{\circ} \mathrm{E}\right)$ as a reference for the DOAS retrieval. Different reference spectra are selected daily for each OMI row and their wavelength registration is optimised as described above. This serves as a first correction for the OMI stripe effect. Consequently, all retrieved slant columns are differential columns relative to the mean reference spectra.

A fifth-order polynomial is used to fit the low-frequency variations of the spectra, as well as a linear offset term. The $\mathrm{H}_{2} \mathrm{CO}$ Meller and Moortgat (2000) laboratory measurements are fitted to the differential absorption features. The absorption cross sections of $\mathrm{O}_{3}$ at 228 and $243 \mathrm{~K}, \mathrm{NO}_{2}$ and $\mathrm{BrO}$ are included. To take into account the Ring effect, two cross sections are used (Vountas et al., 1998). They have been calculated in an ozone-containing atmosphere for low and high SZA (solar zenith angle) using LIDORT RRS (Spurr et al., 2008). Two additional terms (called $\mathrm{O}_{3} \mathrm{~L}$ and $\mathrm{O}_{3} \mathrm{O}_{3}$ in Table 1), resulting from the Taylor expansion of the $\mathrm{O}_{3}$ absorption as a function of the wavelength, are included in order to better cope with strong $\mathrm{O}_{3}$ absorption effects (Puķīe et al; 2010; De Smedt et al., 2012). Introduced in the previous version 12, a second (larger) retrieval interval is used to pre-fit the $\mathrm{BrO}$ slant columns (Fig. 1). The benefit of this procedure is to decorrelate the $\mathrm{H}_{2} \mathrm{CO}$ and $\mathrm{BrO}$ absorption features, resulting in a reduction of the noise on the $\mathrm{BrO}$ and $\mathrm{H}_{2} \mathrm{CO}$ slant columns. However, the $\mathrm{O}_{2}-\mathrm{O}_{2}\left(\mathrm{O}_{4}\right)$ absorption had not been taken into account in version 12, neither in the larger nor in the shorter interval. While the weak and smooth $\mathrm{O}_{4}$ signature appears to be well fitted by the fifth-order polynomial used in the shorter interval (Hewson et al., 2013), not including the stronger $\mathrm{O}_{4}$ term in the larger interval is clearly a shortcoming. Nevertheless, this solution has often been selected in past studies, because experience has shown that including $\mathrm{O}_{4}$ tends to destabilise the BrO fit (Kurosu, 2008; Begoin et al., 2010; Theys et al., 2011), hence leading to increased noise on the $\mathrm{H}_{2} \mathrm{CO}$ slant columns retrieved in the shorter interval. In version 14, we propose the addition of a third fitting interval (339-364 nm) covering the entire $\mathrm{O}_{4}$ absorption band around $360 \mathrm{~nm}$ (Fig. 1). We use the recently published $\mathrm{O}_{4}$ absorption cross sections by Thalman and Volkamer (2013), and our $\mathrm{H}_{2} \mathrm{CO}$ retrieval scheme therefore now includes three fitting intervals: $\mathrm{w} 1$ for the pre-fit of $\mathrm{O}_{4}$, w2 for the pre-fit of $\mathrm{BrO}$, and $\mathrm{w} 3$ for the fit of the $\mathrm{H}_{2} \mathrm{CO}$ slant columns, in which the $\mathrm{O}_{4}$ and $\mathrm{BrO}$ slant columns are fixed to values determined in the other intervals.

It should be noted that for the GOME and SCIAMACHY $\mathrm{H}_{2} \mathrm{CO}$ retrievals, only one retrieval interval is used (328.5$346 \mathrm{~nm}$ ) because the quality of the recorded spectra has been found to be insufficient in the $360 \mathrm{~nm}$ region (De Smedt et al., 2008). $\mathrm{O}_{4}$ absorption effects are therefore significantly reduced.

Figure 2 illustrates the correlation effects occurring between the $\mathrm{O}_{4}, \mathrm{BrO}$ and $\mathrm{H}_{2} \mathrm{CO}$ absorptions, for one OMI orbit on 1 July 2005. The upper panel shows the $\mathrm{O}_{4}$ differential 
Table 1. Summary of retrieval settings used in version 14 of the BIRA $\mathrm{H}_{2} \mathrm{CO}$ retrieval algorithm, applicable to GOME-2 and OMI measurements.

\begin{tabular}{|c|c|}
\hline \multicolumn{2}{|c|}{ Settings for the DOAS equation parameters } \\
\hline Calibration & Accurate solar atlas (Chance and Kurucz, 2010) \\
\hline Slit function & $\begin{array}{ll}\text { OMI: one slit function per binned spec- } & \text { GOME-2: asymmetric Gaussian slit } \\
\text { trum as a function of wavelength (Dob- } & \text { function fitted during calibration (De } \\
\text { ber et al., 2006) } & \text { Smedt et al., 2012) }\end{array}$ \\
\hline Reference spectrum & Daily average of radiances selected in the equatorial Pacific \\
\hline Polynomial & Fifth order \\
\hline Intensity offset & Linear offset \\
\hline Hot pixels treatment & Iterative spike removal algorithm (Richter et al., 2011; De Smedt et al., 2014) \\
\hline \multicolumn{2}{|l|}{ Absorption cross-section data sets } \\
\hline $\mathrm{H}_{2} \mathrm{CO}$ & Meller and Moortgat (2000) \\
\hline $\mathrm{O}_{3}$ & Brion et al. (1998), Daumont et al. (1992), Malicet et al. (1995) \\
\hline $\mathrm{BrO}$ & Fleischmann et al. (2004) \\
\hline $\mathrm{NO}_{2}$ & Vandaele et al. (2002) \\
\hline $\mathrm{O}_{2}-\mathrm{O}_{2}\left(\mathrm{O}_{4}\right)$ & Thalman and Volkamer (2013) \\
\hline Ring effect & Two Ring cross sections calculated in an ozone-containing atmosphere \\
\hline Ring effect & for low and high SZA, using LIDORT RRS (Spurr et al., 2008). \\
\hline Non-linear $\mathrm{O}_{3}$ absorption effect & $\begin{array}{l}\text { Two pseudo cross sections from the Taylor expansion of the wavelength } \\
\text { and the } \mathrm{O}_{3} \text { optical depth (Pukite et al., 2010). }\end{array}$ \\
\hline Fitting interval w1: $\mathrm{O}_{4}$ & $339-364 \mathrm{~nm}$ \\
\hline Included cross sections & $\begin{array}{l}\mathrm{O}_{4}(293 \mathrm{~K}), \mathrm{O}_{3}(228 \mathrm{~K}), \mathrm{BrO}(223 \mathrm{~K}), \\
\mathrm{H}_{2} \mathrm{CO}(298 \mathrm{~K}), \mathrm{NO}_{2}(220 \mathrm{~K}), \mathrm{Ring} 1, \mathrm{Ring} 2\end{array}$ \\
\hline Fitting interval w2: $\mathrm{BrO}$ & $328.5-359 \mathrm{~nm}$ \\
\hline Included cross sections & $\mathrm{BrO}(223 \mathrm{~K}), \mathrm{H}_{2} \mathrm{CO}(298 \mathrm{~K}), \mathrm{O}_{3}(228$ and $243 \mathrm{~K}), \mathrm{NO}_{2}(220 \mathrm{~K})$, \\
\hline Included cross sections & $\mathrm{O}_{4}(293 \mathrm{~K}$, not fitted $), \mathrm{Ring} 1$, Ring $2, \mathrm{O}_{3} \mathrm{~L}, \mathrm{O}_{3} \mathrm{O}_{3}$ \\
\hline Fitting interval w3: $\mathrm{H}_{2} \mathrm{CO}$ & $328.5-346 \mathrm{~nm}$ \\
\hline Included cross sections & $\mathrm{H}_{2} \mathrm{CO}(298 \mathrm{~K}), \mathrm{O}_{3}(228$ and $243 \mathrm{~K}), \mathrm{BrO}(223 \mathrm{~K}$, not fitted $), \mathrm{NO}_{2}(220 \mathrm{~K})$, \\
\hline Incl & $\mathrm{O}_{4}(293 \mathrm{~K}$, not fitted $), \operatorname{Ring} 1, \mathrm{Ring} 2, \mathrm{O}_{3} \mathrm{~L}, \mathrm{O}_{3} \mathrm{O}_{3}$ \\
\hline
\end{tabular}

slant columns retrieved in w1 (339-364 nm, light blue) or in w2 (328.5-359 $\mathrm{nm}$, dark green) as a function of the latitude. The improved quality of the $\mathrm{O}_{4}$ slant columns in $\mathrm{w} 1$ is observed, as expected from Fig. 1. The second and third panels show the differences observed in the $\mathrm{BrO}$ and $\mathrm{H}_{2} \mathrm{CO}$ slant columns, depending on whether $\mathrm{O}_{4}$ is included in the fits or not (v14-v12), as a function of the $\mathrm{O}_{4}$ slant columns. Those differences are shown for two cases: $\mathrm{O}_{4}$ slant columns from w1 (light blue, v14) or from w2 (dark green). The prefit of $\mathrm{O}_{4}$ in w1 reduces the noise on the $\mathrm{O}_{4}, \mathrm{BrO}$ and $\mathrm{H}_{2} \mathrm{CO}$ slant columns in the three intervals. The correlation between the three molecules is not reduced by the introduction of this third interval (the slope of the differences remains the same), but the slant columns are limited to more realistic values for each molecule, allowing for an effective reduction of the noise. It is interesting to note that the observed slopes of the differences in $\mathrm{BrO}$ and $\mathrm{H}_{2} \mathrm{CO}$ columns are exactly the same for GOME-2 and OMI retrievals and for different periods of the years (not shown), pointing to a fundamental spectral effect rather than an instrumental feature.

From Fig. 2, one can conclude that the net effect of including $\mathrm{O}_{4}$ in the fits is a positive correlation of the $\mathrm{H}_{2} \mathrm{CO}$ slant columns with the $\mathrm{O}_{4}$ differential columns, with $\mathrm{H}_{2} \mathrm{CO}$ column deviations of less than $10^{16}$ molec $\mathrm{cm}^{-2}$ but sometimes reaching $2 \times 10^{16}$ molec $\mathrm{cm}^{-2}$ for extreme $\mathrm{O}_{4}$ values. Figure 3 presents $\mathrm{O}_{4}$ differential slant columns retrieved in w1 from OMI measurements in February and August 2007, giving an idea of the spatial distribution of the expected differences.

Over the Pacific Ocean, the $\mathrm{O}_{4}$ differential slant columns are generally positive and increase with the solar zenith angle. Figure 4 presents the averaged zonal variation of the $\mathrm{H}_{2} \mathrm{CO}, \mathrm{BrO}$ and $\mathrm{O}_{4}$ differential slant columns for January, April, July and October 2007, as a function of the latitude (a) when $\mathrm{O}_{4}$ is not included in the fit (v12), and (b) when $\mathrm{O}_{4}$ is pre-fitted in $\mathrm{w} 1$ and included in the fit (v14). Dashed lines show the slant columns before the background normalisation procedure. The decrease of the $\mathrm{H}_{2} \mathrm{CO}$ slant columns with latitude is greatly reduced when $\mathrm{O}_{4}$ is considered, with a minimum impact on the standard deviations of the columns, owing to the pre-fit of $\mathrm{O}_{4}$. However, a positive artificial dependency remains that is related to ozone absorption interferences and still needs to be corrected (see Sect. 3.2). The $\mathrm{O}_{4}$ effect is exactly the opposite for $\mathrm{BrO}$, for which a decrease 

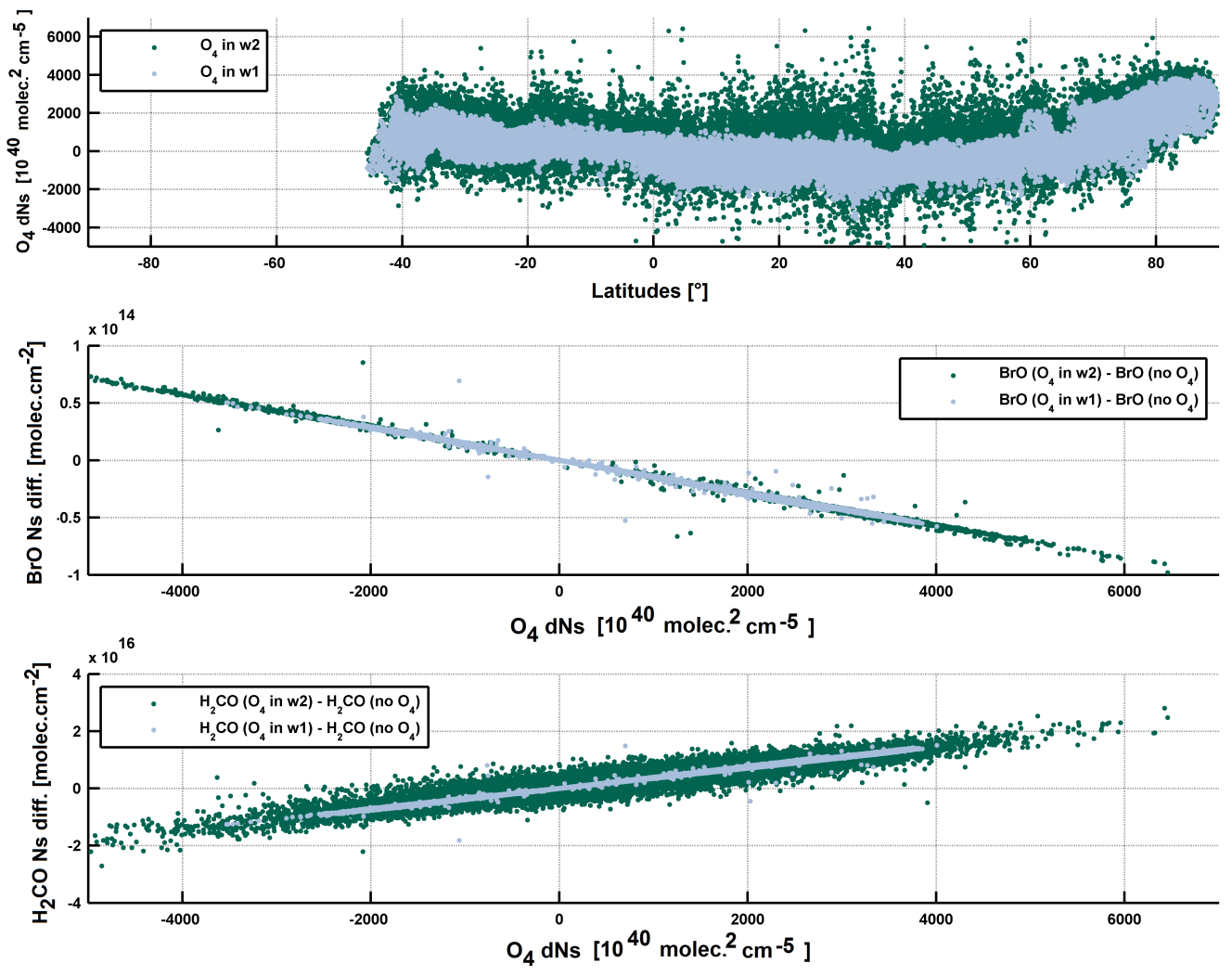

Figure 2. Interdependencies between $\mathrm{O}_{4}, \mathrm{BrO}$ and $\mathrm{H}_{2} \mathrm{CO}$ slant columns shown for one OMI orbit of 1 July 2005 (UT 0548 ). The first panel shows the differential $\mathrm{O}_{4}$ slant columns retrieved in w1 (339-364 nm, light blue) and in w2 (328.5-359 nm, dark green) as a function of the latitude. The second and third panels show the differences obtained in $\mathrm{BrO}$ and $\mathrm{H}_{2} \mathrm{CO}$ slant columns as a function of the $\mathrm{O}_{4}$ slant columns, when including or not including $\mathrm{O}_{4}$ in the fits. Differences are shown for two cases: $\mathrm{O}_{4}$ slant columns retrieved in w1 (light blue) or in w2 (dark green). The limits of the wavelength intervals are indicated in Fig. 1.
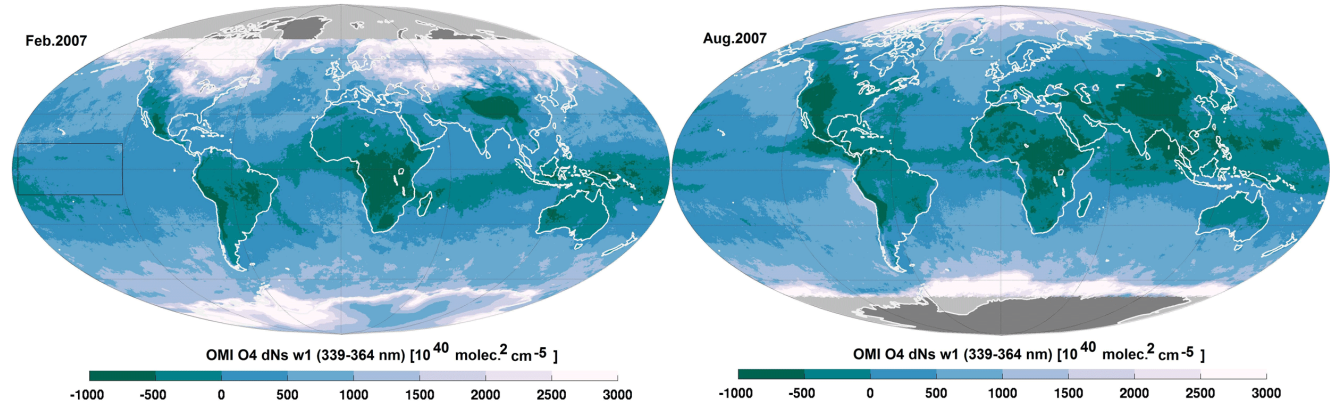

Figure 3. Monthly averaged $\mathrm{O}_{2}-\mathrm{O}_{2}\left(\mathrm{O}_{4}\right)$ differential slant columns retrieved in the interval 339-364 nm. The slant columns are differential since radiance spectra over the equatorial Pacific region (delimited by the black box) are used as reference spectra.

of the columns is observed for large $\mathrm{O}_{4}$ slant columns (about $-20 \%)$. This can have a significant impact for $\mathrm{BrO}$ studies in polar regions (Salawitch et al., 2010; Choi et al., 2012), but it is beyond the scope of this paper.

Over the continents, where $\mathrm{H}_{2} \mathrm{CO}$ column enhancements are expected, the differential $\mathrm{O}_{4}$ slant columns are almost always negative (i.e. lower than over oceans), due to the combined effect of higher altitude and lower surface reflectivity.
We observe therefore a decrease of the $\mathrm{H}_{2} \mathrm{CO}$ columns over continental emission regions, by 0 down to $-25 \%$. This reduction is the same for GOME-2 and OMI; that is, it has no impact on the observed diurnal variations. As an example, Fig. 5 presents the time series of GOME-2 and $\mathrm{OMI} \mathrm{H}_{2} \mathrm{CO}$ columns over India and equatorial Africa, representative for mid-latitudes and tropical emission regions. Results without (v12) and with (v14) $\mathrm{O}_{4}$ are plotted, as well as the differ- 

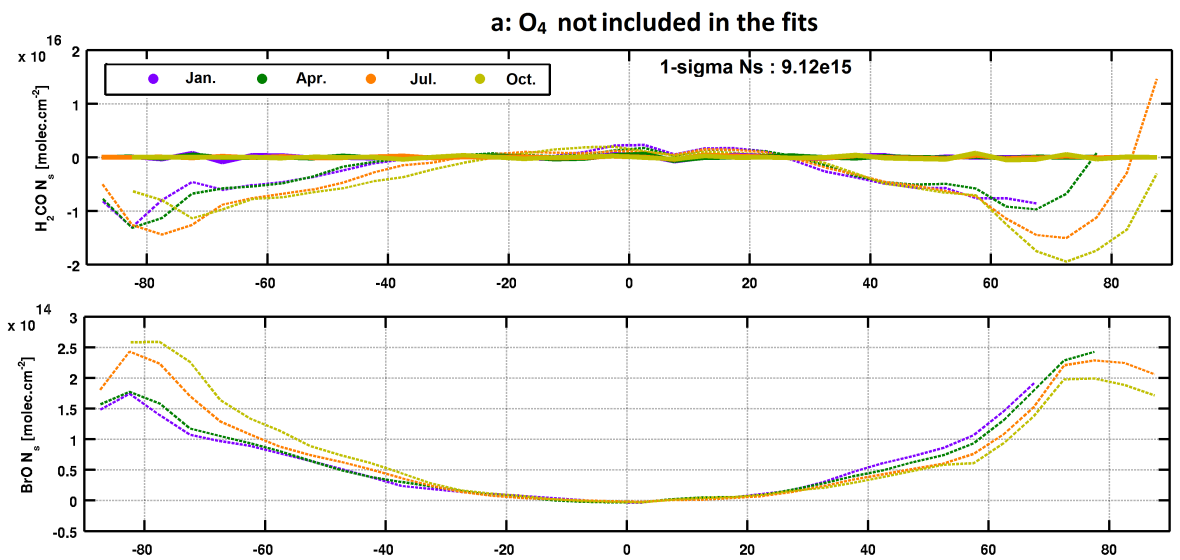

b: $\mathrm{O}_{4}$ included in the fits
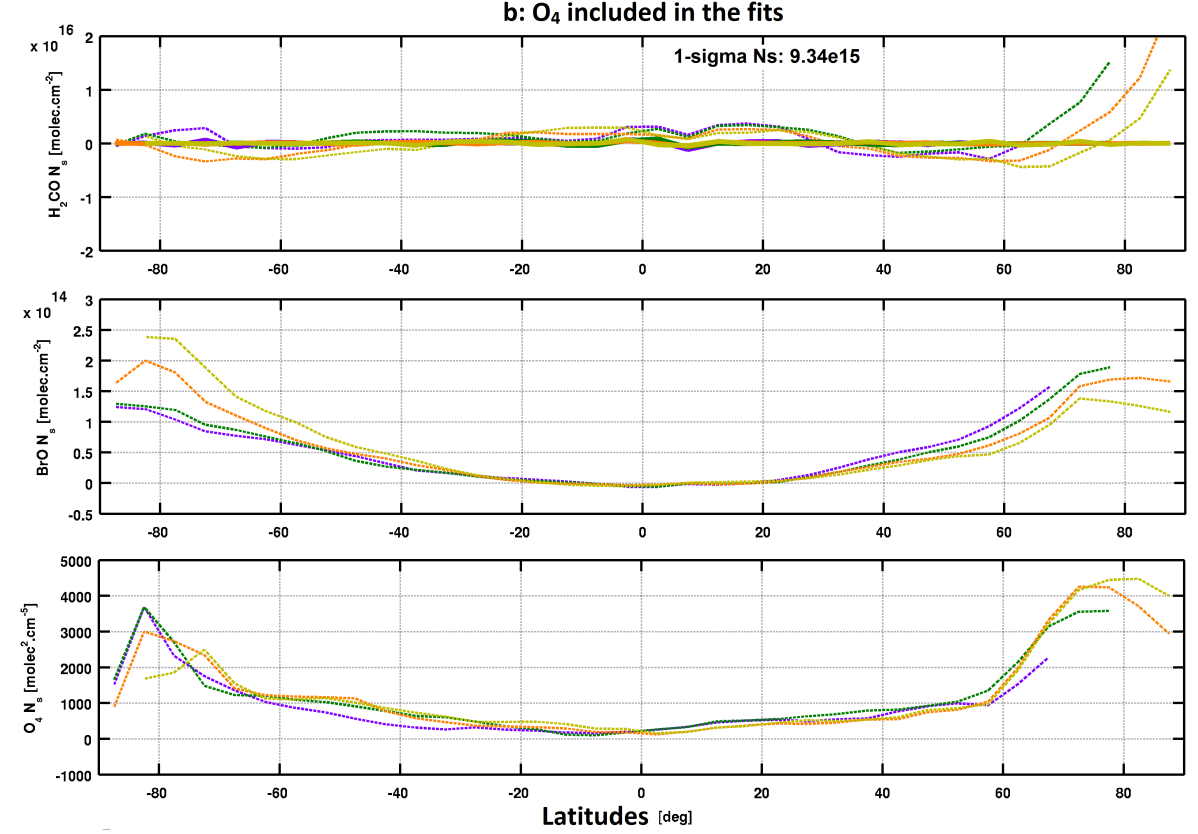

Figure 4. Averaged zonal variation of the $\mathrm{H}_{2} \mathrm{CO}, \mathrm{BrO}$ and $\mathrm{O}_{4}$ differential slant columns for 4 months of OMI observations in 2005 (January, April, July, October), over the Pacific Ocean, as a function of the latitude (a) when $\mathrm{O}_{4}$ is not included in the fit (v12), and (b) when $\mathrm{O}_{4}$ is included and pre-fitted in w1 (v14). Dashed lines show the slant columns before the background normalisation procedure, while the plain lines show the normalised $\mathrm{H}_{2} \mathrm{CO}$ slant columns.

ences between OMI and GOME-2 for the two versions. A reduction of the columns is observed when including $\mathrm{O}_{4}$ in the fits, but the OMI-GOME-2 differences are equivalent for v12 and v14.

\subsection{Across-track and zonal reference sector correction}

The use of daily radiance spectra as a reference for the DOAS retrievals results in differential slant columns close to zero in the equatorial Pacific. However, latitude-dependent biases in the $\mathrm{H}_{2} \mathrm{CO}$ columns, due to unresolved spectral interferences, remain a limiting factor for the DOAS retrieval of weak absorbers such as $\mathrm{H}_{2} \mathrm{CO}$. Furthermore, in the case of a 2-D detector array such as OMI, across-track striping arises, due to imperfect calibration and different dead/hot pixel masks for the detectors. Such instrumental effects also affect scanning spectrometers like GOME-2, but since these instruments have one single detector, these errors do not appear as stripes, but rather as constant offsets (Boersma et al., 2011). These different retrieval artefacts can be compensated for to a certain extent, using normalisation approaches such as the reference sector correction (Kurosu, 2008; De Smedt et al., 2008). As for the DOAS reference radiance selection, the reference sector is chosen in the Pacific Ocean, where the only significant source of $\mathrm{H}_{2} \mathrm{CO}$ is the $\mathrm{CH}_{4}$ oxidation. The $\mathrm{H}_{2} \mathrm{CO}$ background is replaced by model simulations in the same region. The reference sector correction is also meant to handle possible time-dependent instrumental degradation ef- 

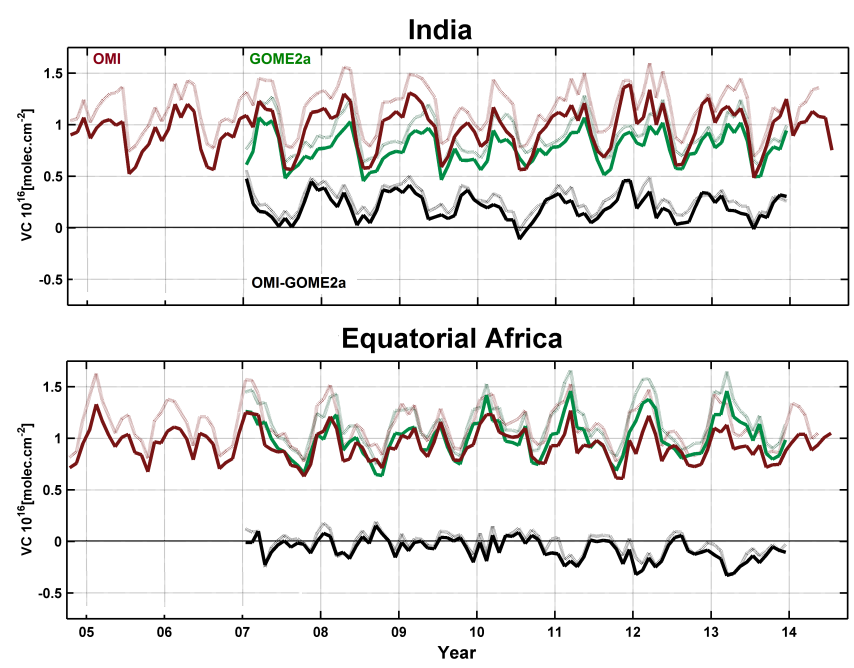

Figure 5. Impact of $\mathrm{O}_{4}$ on the absolute $\mathrm{OMI}$ and GOME-2A $\mathrm{H}_{2} \mathrm{CO}$ columns (respectively in red and green) and on their differences (in black). Dashed lines show results when $\mathrm{O}_{4}$ is not included in the fits, while solid lines show v14 results.

fects, for example the evolution of the OMI stripe artefacts, or the GOME-2 signal degradation (De Smedt et al., 2012). Note that our analysis shows that the most efficient method to reduce across-track stripes in $\mathrm{OMI} \mathrm{H}_{2} \mathrm{CO}$ retrievals is to use row-dependent mean radiances as a reference spectrum in the DOAS equation (see Sect. 3.1).

We apply a two-step normalisation of the $\mathrm{H}_{2} \mathrm{CO}$ slant columns. In a first step, a row-dependent median $\mathrm{H}_{2} \mathrm{CO}$ value is determined in the equatorial Pacific $\left(15^{\circ} \mathrm{S}-15^{\circ} \mathrm{N}\right.$, $180-240^{\circ}$ E) and subtracted from all the columns (in the case of GOME-2, we use a viewing angle-dependent correction). The aim is to reduce possible remaining offsets between rows, resulting from the different detectors. In addition to the destriping procedure, those OMI rows presenting a level of noise and fitting residuals significantly higher than the average of the other rows for a particular day, are assigned a bad-quality flag and not further used in our applications. This criterion removes a few rows from the analysis in 2005 and, more importantly, all the rows affected by the row anomaly which started in June 2007, and further developed over the years (http://www.knmi.nl/omi/research/product/rowanomalybackground.php). As illustrated by the first line of Fig. 6, the affected rows can be identified using the fitting residuals. This filtering procedure is less systematic than the use of flags provided in the level-1 files, and is aimed to keep as many observations as possible in the analysis, which is of fundamental importance to mitigate the noise on formaldehyde observations. In a second step, the latitudinal dependency of the offset-corrected $\mathrm{H}_{2} \mathrm{CO}$ slant columns is modelled by a polynomial in the entire reference sector $\left(90^{\circ} \mathrm{S}-90^{\circ} \mathrm{N}, \quad 180-240^{\circ} \mathrm{E}\right)$. These two corrections are sequentially subtracted from the global slant columns and replaced by the latitudinal dependency of the modelled columns in the same region. The result of the across-track and zonal reference sector correction is illustrated in Fig. 4 as a function of the latitude and in the second line of Fig. 6, showing daily maps of normalised $\mathrm{OMI} \mathrm{H}_{2} \mathrm{CO}$ slant columns in 2005 and 2014. The loss of coverage due to the OMI row anomaly and to our filtering scheme is clearly visible when comparing the 2005 and 2014 maps.

\subsection{Air mass factors}

In the troposphere, scattering by air molecules, clouds and aerosols leads to complex altitude-dependent air mass factors. Multiple scattering calculations are required for the determination of the air mass factors, and the vertical distribution of the absorber has to be assumed a priori. In the case of optically thin absorbers, the formulation of Palmer et al. (2001) is used and has been described for the TEMIS $\mathrm{H}_{2} \mathrm{CO}$ retrievals in De Smedt et al. (2012). It decouples the vertical sensitivity of the measurements (the scattering weighting functions, derived with radiative transfer model calculations) from the vertical profile shape of the species of interest (vertical shape factors, taken from an atmospheric chemistry transport model or from some other prior knowledge of the vertical distribution of the absorber). Details on these two calculation steps are given below. The decoupling of the AMF calculation allows one to address separately the radiative transfer effects, including clouds, and the atmospheric composition of optically thin absorbers like $\mathrm{H}_{2} \mathrm{CO}$. Vertical columns might be improved for particular locations by using more accurate a priori profiles, for example based on input from regional models, ground-based or aircraft measurements. Furthermore, using shape factors from an atmospheric chemistry model ensures consistency for subsequent evaluation of the model with the retrieved vertical columns (Barkley et al., 2013). For these reasons, the averaging kernels and the a priori profiles are provided in the level-2 data files for each individual measurement. The third line of Fig. 6 presents global daily maps of AMF in April 2005 and 2014. These maps have been filtered for effective cloud fractions larger than 0.4. Clouds and a priori profile shapes are further discussed below and in the validation Sect. 5.2.

\subsubsection{Scattering weighting functions}

Scattering weighting functions calculated at $340 \mathrm{~nm}$ using the LIDORT v3.3 radiative transfer model (Spurr, 2008) are tabulated according to their dependencies with solar, viewing and relative azimuth angles, surface altitude and surface reflectivity. We use the surface reflectivity database derived from OMI by Kleipool et al. (2008), in both GOME-2 and OMI $\mathrm{H}_{2} \mathrm{CO}$ retrievals. Radiative cloud effects are corrected using the independent pixel approximation (IPA, Martin et al., 2002) and the respective cloud products of the instru- 

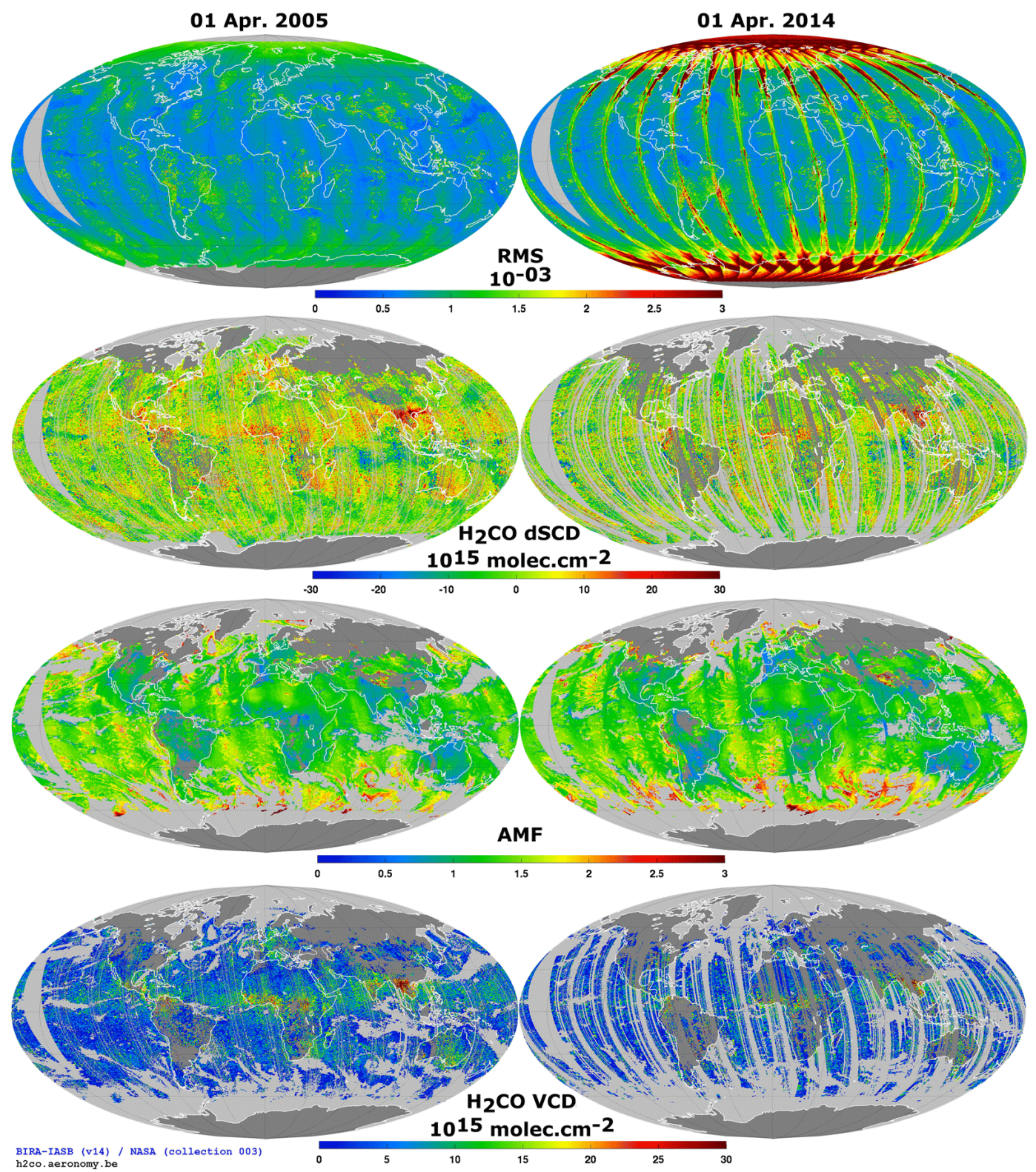

Figure 6. Intermediate retrieval quantities of the $\mathrm{H}_{2} \mathrm{CO}$ retrieval algorithm illustrated with OMI on 1 April 2005 (first column) and 1 April 2014 (second column). The first line shows the fit residuals, while lines 2 to 4 show respectively the $\mathrm{H}_{2} \mathrm{CO}$ reference sector corrected slant columns, the air mass factors and the vertical columns.

ments provided on the TEMIS website, namely the GOME$2 \mathrm{O}_{2}$ A-band Frescov6 product (Wang et al., 2008) and the $\mathrm{OMI} \mathrm{O}_{4}$ cloud product (Stammes et al., 2008). While the cloud fractions are in general good agreement between OMI and GOME-2, we observe larger discrepancies for the cloud altitudes. The differences between OMI and GOME- 2 cloudfree AMFs range from 0 to $-10 \%$ (observation geometry effects), but the differences between IPA cloud-corrected AMFs can reach $-20 \%$ where and when the cloud lies in the lower troposphere. This implies an uncertainty of about $10 \%$ in the final product, since it is not clear whether those cloud- related differences reflect real differences in cloud properties or differences in the cloud retrieval algorithms. This stresses the need for a multi-instrument homogenised cloud product, for example based on the $\mathrm{O}_{4}$ absorption band that can be measured by all sensors. No explicit correction is applied for aerosols, but the cloud correction scheme accounts for a large part of their scattering effect (Boersma et al., 2011). The uncertainty related to aerosol effects is estimated to be lower than $15 \%$ in average (Leitão et al., 2008; Castellanos et al., 2015; Theys et al., 2015). 


\subsubsection{Vertical shape factors: IMAGESv2}

The a priori profile shapes are extracted from daily simulations performed with the IMAGES model, at 09:30 for GOME-2 and 13:30 for OMI. The IMAGESv2 CTM (chemistry transport model) calculates the global distributions of 90 long-lived and 41 short-lived trace gases at a resolution of $2^{\circ}$ (latitude) $\times 2.5^{\circ}$ (longitude) and on 40 vertical levels from the surface to the lower stratosphere. The current model version is thoroughly described in Stavrakou et al. (2013). The model time step is set to $4 \mathrm{~h}$. Diurnal changes in the photolysis and kinetic rates, meteorological fields, and the emissions are taken into account through correction factors calculated from a simulation with a 20 min time step (Stavrakou et al., 2009a) and applied to model runs using longer time steps. Simulations have been performed for all years between 2005 and 2013, spun up by a period of 4 months.

Anthropogenic VOC emissions are obtained from the RETRO 2000 global database (Schultz et al., 2008) and are kept constant throughout the years. Over Asia, RETRO is overwritten by the REASv2 inventory (Kurokawa et al., 2013) until 2008, whereas 2008 values are used for more recent years. Anthropogenic VOC emissions are equal to 147 and $150 \mathrm{Tg}$ VOC in 2005 and 2006, respectively, and to $156 \mathrm{Tg}$ VOC for the following years. Emissions of isoprene from vegetation are taken from the MEGAN-MOHYCANv2 inventory (Stavrakou et al., 2014). The global annual fluxes range between 323 and $363 \mathrm{Tg}$ isoprene, the lowest and the highest values corresponding to 2008 and to 2010, respectively. Open biomass burning emissions are taken from the GFEDv3 inventory (van der Werf et al., 2010) until 2011, whereas a climatological mean based on 1997-2011 GFEDv3 emissions is used for 2012 and 2013. Global annual fire emissions range between $70 \mathrm{Tg}$ VOC (in 2009) and $105 \mathrm{Tg}$ VOC (in 2010).

The photochemical production of $\mathrm{H}_{2} \mathrm{CO}$ is estimated at ca. $1600 \mathrm{Tg}$ annually. The main formaldehyde sinks are the oxidation by $\mathrm{OH}$ (Sander et al., 2011) which leads to $\mathrm{CO}$ production and conversion of $\mathrm{OH}$ to $\mathrm{HO}_{2}$, and two photolysis reactions which produce $\mathrm{CO}$ and $\mathrm{HO}_{2}$ radicals. Based on IMAGESv2 model calculations, photolysis is by far the dominant removal process, estimated at $71 \%$ of the global sink, whereas the OH sink is less efficient $(26 \%)$. Dry and wet deposition account for the remainder $(<3 \%)$. The global photochemical $\mathrm{H}_{2} \mathrm{CO}$ lifetime is estimated at $4.5 \mathrm{~h}$.

\subsection{Quality criteria of the $\mathrm{H}_{2} \mathrm{CO}$ vertical columns}

The $\mathrm{H}_{2} \mathrm{CO}$ level-2 files of version 14 are provided in HDF5 format. They include all the intermediate quantities of the $\mathrm{H}_{2} \mathrm{CO}$ retrieval from slant columns to vertical columns, air mass factors (cloud free or including the IPA cloud correction) and averaging kernels. A detailed error budget is also provided. Error contributions resulting from each step of the retrieval to the final vertical column error are provided sep- arately, including their random and systematic parts (for details, see De Smedt et al., 2014). This allows for an estimation of the total error on the column averages. A quality flag is also provided for each observation. The following criteria are considered for assigning a bad-quality $(<0)$ flag:

- per orbit: fit residuals larger than 3 times the averaged fit residual

- per day: unsuccessful across-track and zonal reference sector correction (see Sect. 3.2)

- per orbit: corrected slant columns lower than the mean corrected column minus 3 times the column standard deviations

- per pixel: effective cloud fractions larger than 0.4

- per pixel: snow or ice flag in the cloud product

- per pixel: solar zenith angles larger than $70^{\circ}$

- per pixel: individual vertical column errors larger than 3 times the column

\section{GOME-2 and OMI $\mathrm{H}_{2} \mathrm{CO}$ vertical columns}

\subsection{Background values and precision}

Figure 7 presents time series of monthly averaged GOME2A, GOME-2B and $\mathrm{OMI} \mathrm{H}_{2} \mathrm{CO}$ vertical columns in the reference sector (first panel) together with the retrieval residuals, standard deviations and number of observations (second to fourth panels). In the first panel, uncorrected columns are displayed with dotted lines, while background-corrected columns are represented with plain lines. From this figure, it can be concluded that even the uncorrected $\mathrm{OMI} \mathrm{H}_{2} \mathrm{CO}$ columns are remarkably stable in time (yet across-track and zonal corrections are needed). In the case of GOME-2A retrievals, however, the use of radiances as DOAS reference spectra does not completely compensate for a weakening of the signal over the years, although the loss of signal is reduced by a factor of 2 compared to the use of solar irradiances, as was the case in version 12 (De Smedt et al., 2012).

Regarding the fit residuals and the standard deviations of the monthly averaged $\mathrm{H}_{2} \mathrm{CO}$ columns, the OMI retrievals also show a very good stability in time, the random errors having increased by less than $4 \%$ in 10 years, while the GOME-2A random errors have increased at a rate of about $10 \%$ per year due to degradation effects. Accordingly, the $\mathrm{OMI} \mathrm{H}_{2} \mathrm{CO}$ individual pixel precision is about $7 \times 10^{15} \mathrm{molec}^{-2}$, while the GOME-2A precision degraded from $5 \times 10^{15}$ to $8 \times 10^{15}$ molec $\mathrm{cm}^{-2}$. The GOME-2B performances are found to be equivalent to those of GOME$2 \mathrm{~A}$ in its early lifetime; however, a degradation rate similar to the one of GOME-2A is expected. 

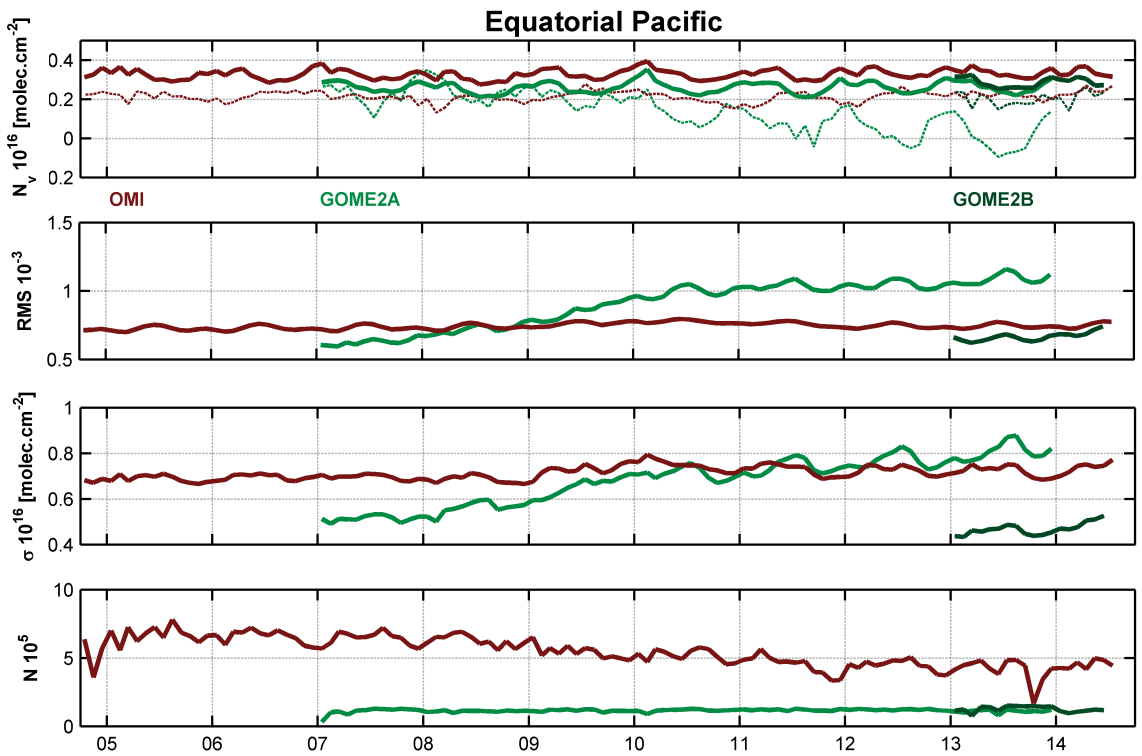

Figure 7. Time series of $\mathrm{H}_{2} \mathrm{CO}$ retrieval statistics for OMI and GOME-2 on METOP-A and MetOp-B in the remote equatorial Pacific region $\left([-15,15]^{\circ}\right.$ lat., $[180,240]^{\circ}$ long.). The first panel presents the $\mathrm{H}_{2} \mathrm{CO}$ vertical columns, before and after background correction (dotted and plain lines). The second, third and fourth panels present respectively the fit residuals, the column standard deviation and the number of valid observations. See text for details on the DOAS retrieval settings.

As shown in the fourth panel, the number of OMI observations passing our quality criteria has decreased by $40 \%$ since the beginning of the mission due to the row anomaly issue. The resulting change of sampling has an impact on the calculated monthly means that should be taken into account in trend analyses (see Sect. 6).

\subsection{Continental emission regions}

Figure 8 presents multi-year maps of $\mathrm{H}_{2} \mathrm{CO}$ vertical columns retrieved from GOME-2A and OMI between 2007 and 2013, and their averaged absolute differences over the same period. For these maps (and further below), the quality flags as defined in Sect. 3.4 have been used to filter out invalid satellite observations. We observe consistent $\mathrm{H}_{2} \mathrm{CO}$ distributions, with the highest columns over tropical regions, India, China, south-eastern China and the south-eastern US. We also observe noticeable differences, OMI showing more elevated columns at mid-latitudes and over regions with moderate $\mathrm{H}_{2} \mathrm{CO}$ concentrations, but lower columns in the tropics, where the $\mathrm{H}_{2} \mathrm{CO}$ columns are highest. To better visualise the regional structures, Fig. 9 presents $\mathrm{H}_{2} \mathrm{CO}$ vertical columns derived from both sensors over Europe (from April to September) and Asia (from March to November), averaged between 2007 and 2013.

Different effects can be identified.

1. The better horizontal resolution of OMI allows for a better identification of strong hotspots over localised $\mathrm{H}_{2} \mathrm{CO}$ sources, as for example over cities like Mexico City, Pretoria, Hong Kong/Guangdong, Beijing, Cairo,
Tehran and Mumbai. This resolution effect can also be identified along coastal areas (Cape Town (South Africa), the Algerian coast, the Turkish coasts, Kerala (India) or California (US)) and along mountain chains (north of India, Pyrenees, Alps).

2. The increase in $\mathrm{H}_{2} \mathrm{CO}$ columns between 09:30 and 13:30 appears to be largest over southern Europe, southern Australia, north-eastern China or central Siberia, while an inverse diurnal variation, of equivalent magnitude, is observed over the equatorial forests of the Amazon, Africa and Indonesia. The same effect has been reported for glyoxal columns, another important indicator of NMVOC emissions (Alvarado et al., 2014). The observed diurnal variations will be further discussed in Sect. 5, using ground-based observations.

3. Differences in retrieval sensitivity appear when comparing GOME-2 and OMI. We note that over oceans, poleward of $30^{\circ}$, OMI columns are found to be higher than GOME-2. These differences cannot be explained only by the diurnal variation of the $\mathrm{CH}_{4}$ oxidation, but they also result from a relative lack of sensitivity of GOME2 to lower tropospheric $\mathrm{H}_{2} \mathrm{CO}$ in comparison to OMI. This is due to the morning overpass time of GOME-2, which leads to larger SZA over middle and high latitudes (and therefore to lower sensitivity to the lowest atmospheric layers) and to lower $\mathrm{H}_{2} \mathrm{CO}$ concentrations (and therefore to lower absorption).

Table 2 provides a list of regions where the highest annual $\mathrm{H}_{2} \mathrm{CO}$ columns are observed. The annual means are pro- 


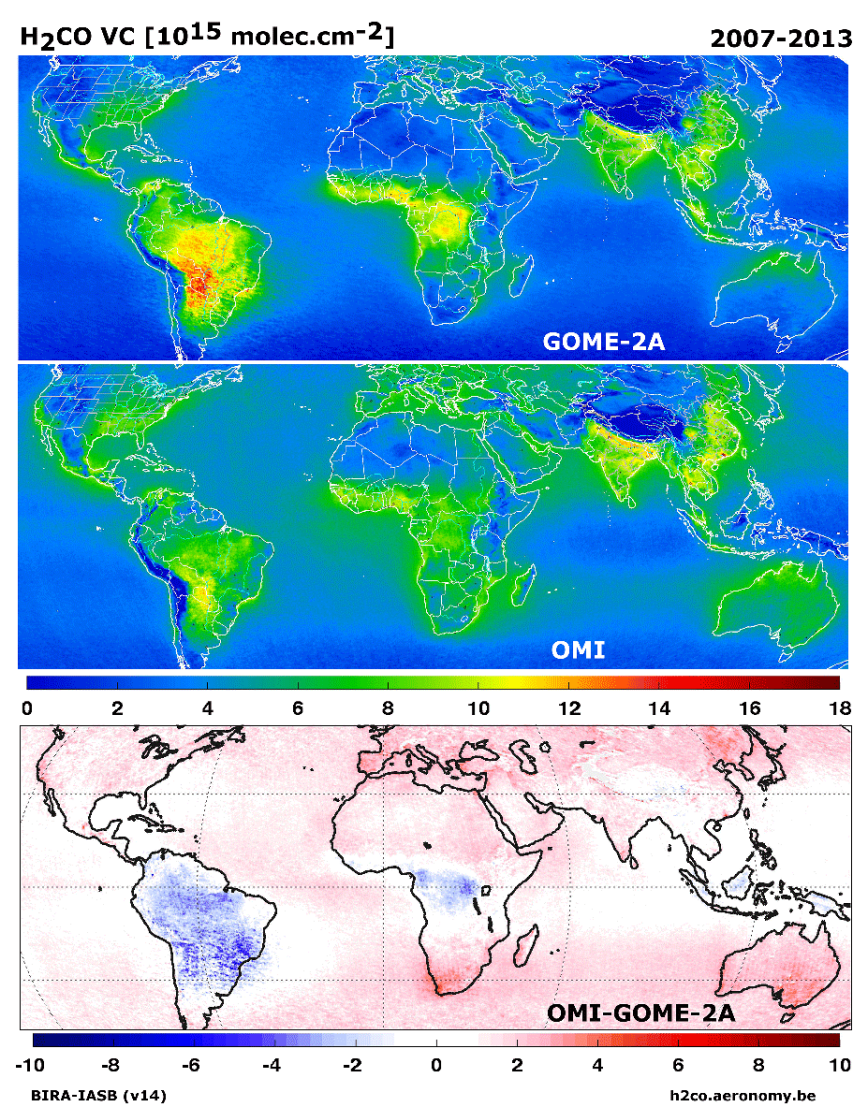

Figure 8. $\mathrm{H}_{2} \mathrm{CO}$ vertical columns retrieved from GOME-2/MetOpA (first panel, EUMETSAT level-1 data), OMI/Aura (second panel, NASA level-1 data), and their absolute differences (third panel) between 2007 and 2013.

vided with the standard deviations of the monthly averaged columns, as an indication of the amplitude of the seasonal variations. The same regions stand out in both the GOME-2 and OMI observations, with equivalent seasonal variations. However, as shown on the maps, the GOME-2 observations are maximal in the tropics (Africa and South America), while the OMI observations maximise over megacities like Hong Kong/Guandong or Delhi. As can be deduced from the seasonal deviations provided in Table 2, the largest seasonal variations are found in Rondônia (Brazil) and Tianjin (China), for both instruments. Interestingly, the $\mathrm{OMI} \mathrm{H}_{2} \mathrm{CO}$ columns exhibit large seasonal variations along the coasts of India, which are less pronounced in GOME-2 observations (Goa, Kerala, Orissa). This could be explained by resolution effects or by diurnal variations in the $\mathrm{H}_{2} \mathrm{CO}$ production and loss processes during the monsoon season. In Sect. 6, the complete time series of monthly averaged $\mathrm{H}_{2} \mathrm{CO}$ vertical columns in China, India, Africa, South America, North America and Europe are presented.

\section{Validation using MAX-DOAS measurements}

We validate the observed satellite column variations using ground-based measurements operated by BIRA-IASB at seven stations: Cabauw, Brussels, the Haute-Provence Observatory, Beijing, Xianghe, Bujumbura and Reunion. Details of the ground-based measurements, and related publications, are summarised in Table 3. In Reunion, measurements have been performed with an FTIR instrument (Vigouroux et al., 2009), while at all other stations, multi-axis DOAS (MAXDOAS) instruments have been used. Although installed at the end of 2013, the Bujumbura instrument could only deliver 6 months of data due to a failure of the UV channel in April 2014.

The MAX-DOAS measurement technique has been developed to retrieve tropospheric trace gas total columns and profiles. The most recent generation of MAX-DOAS instruments allows for measurement of aerosols and a number of tropospheric pollutants, such as $\mathrm{NO}_{2}, \mathrm{H}_{2} \mathrm{CO}, \mathrm{SO}_{2}, \mathrm{HONO}$, $\mathrm{O}_{4}$ and CHOCHO (see e.g. Heckel et al., 2005; Clémer et al., 2010; Irie et al., 2011; Ma et al., 2013; Hendrick et al., 2014; Vlemmix et al., 2014; Wang et al., 2014). $\mathrm{H}_{2} \mathrm{CO}$ slant columns have been retrieved from the six MAX-DOAS instruments using consolidated settings published in Pinardi et al. (2013). While the scientific-grade instruments installed in China and in Bujumbura allow for vertical profile retrievals by optimal estimation (Clémer et al., 2010; Hendrick et al., 2014), only vertical columns could be retrieved from the less sensitive instruments operated at the other stations. We therefore use the ground-based total columns to validate the seasonal and diurnal variations in all stations, while a more quantitative validation making use of the profile information is performed in Beijing/Xianghe and Bujumbura.

\subsection{Seasonal and diurnal variations}

Figure 10 presents the mean diurnal variations of the $\mathrm{H}_{2} \mathrm{CO}$ columns, averaged by season over the complete period of measurements, as observed from the ground (in black) and from space (in red). For this figure, measurements in Cabauw and Brussels have been combined, as well as those in Beijing and Xianghe. We therefore consider five validation sites, representative for different emission sources and illumination conditions. The satellite observations are averaged within $100 \mathrm{~km}$ around each station, and filtered as described in Sect. 3.4. Although larger than the typical length of air masses sampled by a MAX-DOAS spectrometer, which is less than a few tens of kilometres (Gomez et al., 2014), this radius allows inclusion of enough satellite pixels to ensure significant analysis. MAX-DOAS observations are filtered using similar thresholds on total errors (retrieval errors larger than 3 times the columns) and solar zenith angles $\left(70^{\circ}\right)$. Cloudy observations are excluded using the multiplescattering cloud filter described in Gielen et al. (2014) since such sky conditions can potentially degrade the quality of 

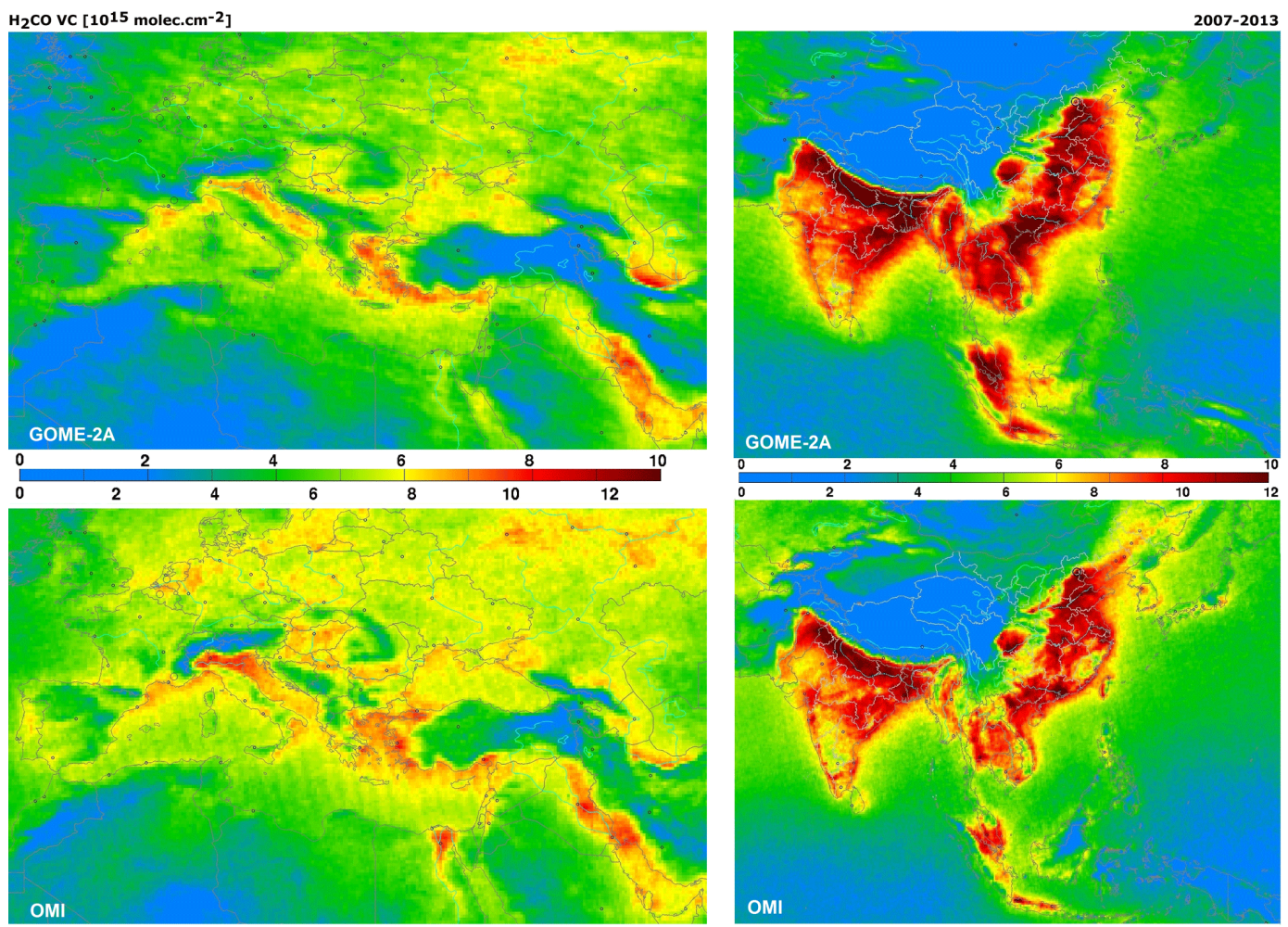

Figure 9. $\mathrm{H}_{2} \mathrm{CO}$ vertical columns retrieved from GOME-2/MetOp-A (first row) and OMI/Aura (second row) over Europe (from April to September) and Asia (from February to November), between 2007 and 2013. Note that different colour scales have been used for GOME-2 and OMI.

the MAX-DOAS retrievals. The error bars shown in Fig. 10 include random and systematic error contributions. The random errors are taken as the standard deviations of the daily averaged observations divided by the square root of the number of days considered in the seasonal means. Wintertime satellite columns in Europe and China are not shown, because of their reduced quality resulting from a combination of low $\mathrm{H}_{2} \mathrm{CO}$ values and lower satellite sensitivity close to the surface. Furthermore, Table 4 provides quantitative differences between the afternoon and morning observations for the five locations, in each season. Both for satellite and ground-based measurements, the correlations between 09:30 and 13:30 columns have been considered to estimate the error in the differences, using a standard uncertainty propagation formulation.

The first conclusion that can be drawn from Fig. 10 is the general underestimation of the satellite columns by 0 up to $50 \%$ compared to the MAX-DOAS observations, especially during the seasons of maximum concentration. In comparison, the agreement is found to be better with tropical background FTIR measurements (Vigouroux et al., 2009). The second conclusion is the qualitative agreement between the satellite and ground-based measurements regarding the $\mathrm{H}_{2} \mathrm{CO}$ column variations. The seasonal variations are in very good agreement, with a maximum in summertime in mid- latitude regions, especially in the south of France and in China. Regarding diurnal variations, the differences between the OMI and GOME-2 columns should reflect the change in $\mathrm{H}_{2} \mathrm{CO}$ between 09:30 and 13:30. However, uncertainties in the satellite $\mathrm{H}_{2} \mathrm{CO}$ columns are large (De Smedt et al., 2012), and so are the errors in their differences, as reflected in Table 4. Nevertheless, the sign of the differences between GOME-2 and OMI agrees well with both MAX-DOAS and FTIR measurements. Early afternoon values are almost always equal to or larger than mid-morning values, except in Bujumbura, where morning columns are larger. The amplitude of the diurnal variation inferred from ground-based and satellite data is also in relatively good agreement, as can be seen by comparing the slopes between 09:30 and 13:30, and from Table 4. This is less true for summertime columns in Brussels/Cabauw, or for springtime columns in OHP and in Beijing/Xianghe, where the differences in OMI-GOME-2 are larger than the corresponding MAX-DOAS variations, possibly pointing to an underestimation of the GOME-2 retrievals in those regions/periods.

\subsection{Vertical columns in China and in Burundi}

Monthly averaged columns retrieved from GOME-2, OMI and MAX-DOAS measurements are shown in Figs. 11 and 

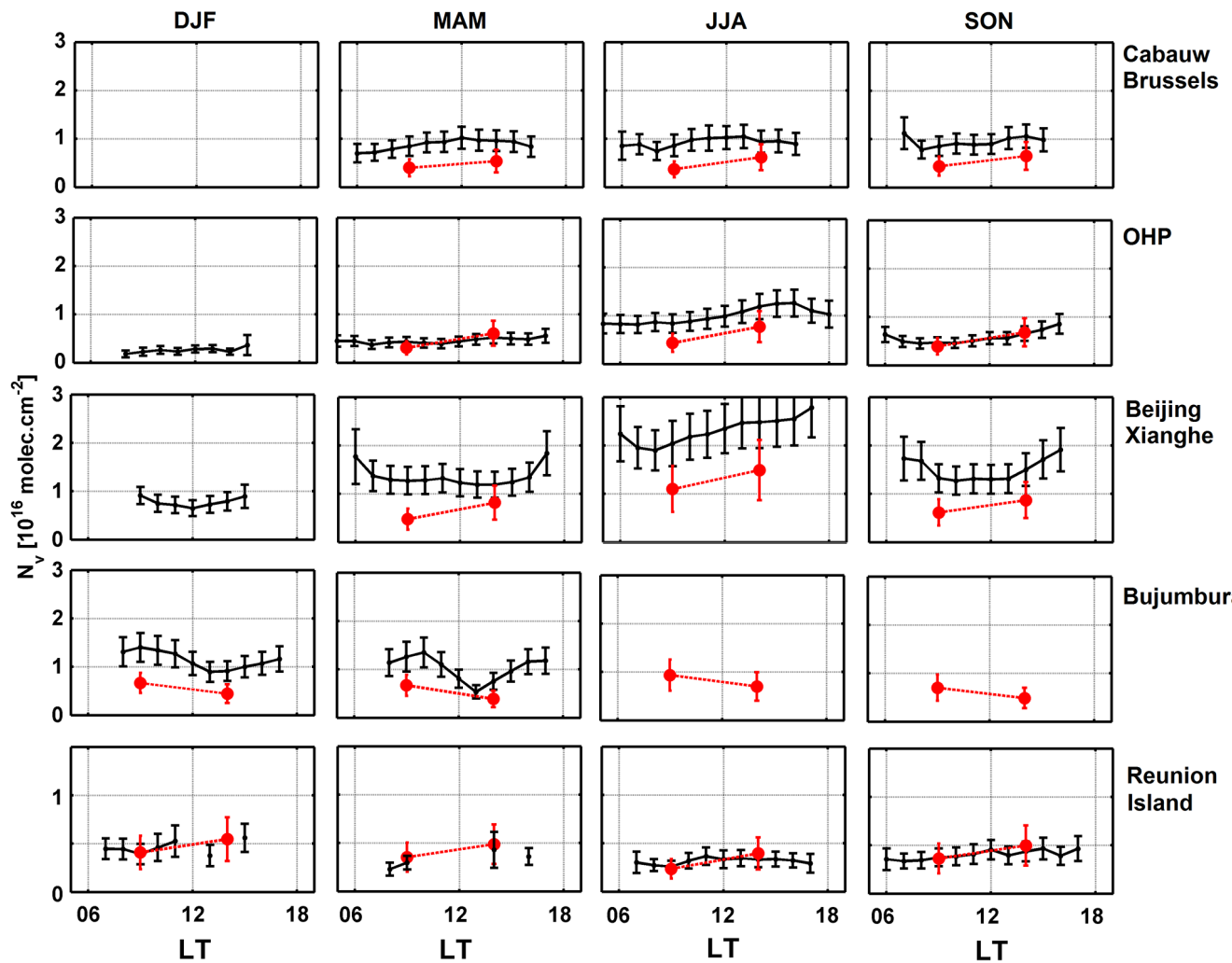

OHP
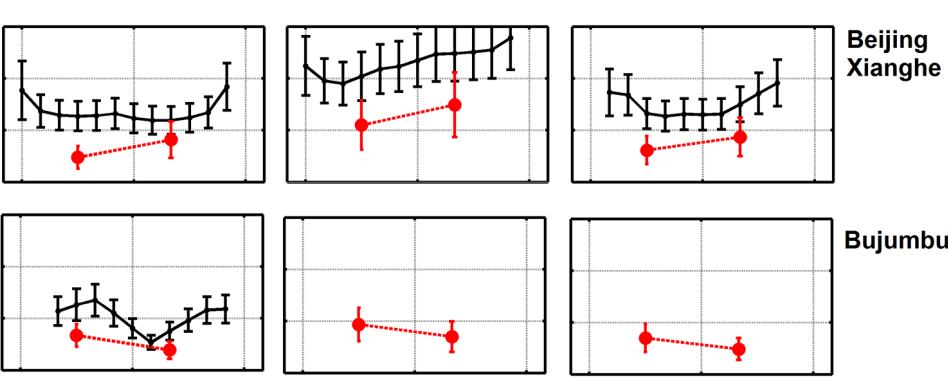

Bujumbura
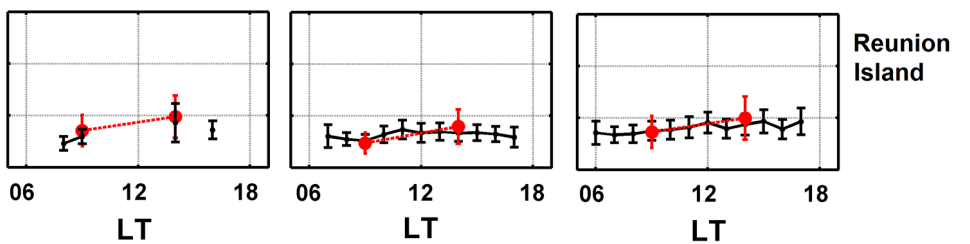

Figure 10. Mean seasonal and diurnal variations of the $\mathrm{H}_{2} \mathrm{CO}$ columns as observed by MAX-DOAS or FTIR instruments (in black) and by GOME-2 and OMI (in red). Values are shown for five regions where BIRA-IASB operates ground-based measurements: Cabauw and Brussels (northern Europe), OHP (southern France), Beijing and Xianghe (north-eastern China), Bujumbura (central Africa) and Reunion (southern Africa). Satellite measurements have been averaged within $100 \mathrm{~km}$ around each location, and filtered using quality criteria as defined in Sect. 3.4. Details of the ground-based measurements are summarised in Table 3.

12, respectively, for the stations of Beijing/Xianghe (averaged over 2008-2013) and Bujumbura (averaged over 20132014). As the instrument in Bujumbura was installed at the end of 2013, we use the more recent $\mathrm{H}_{2} \mathrm{CO}$ columns from GOME-2B, but the GOME-2A columns are shown up to the end of 2013 (light green). The monthly means have been calculated using days in common between, respectively, GOME-2 and morning MAX-DOAS data (08:00-11:00), and OMI and afternoon MAX-DOAS data (12:00-15:00). Again, the satellite observations are averaged within $100 \mathrm{~km}$ around each station and filtered as described in Sect. 3.4. In China, the resulting number of correlative days amounts to 711 for GOME-2 and 807 for OMI. In Burundi, we obtain respectively 58 and 90 days over the 5 months of measurements. Quantitative comparisons between GOME-2, OMI and MAX-DOAS columns are provided in Table 5. Three sets of monthly averages are used for the satellites, in order to evaluate uncertainties related to the AMF calculation: (1) the vertical columns calculated using the IMAGES a priori profile shapes and no cloud correction (plain dots), (2) same but applying the IPA to correct for cloud radiative effects (empty dots), and (3) the vertical columns calculated using as a priori the $\mathrm{H}_{2} \mathrm{CO}$ vertical profile shapes retrieved from the MAX-DOAS measurements and the IPA cloud correction (diamonds). In Fig. 11, the lower panels display scatter plots between monthly averaged observations for the satellite retrievals versions (2) and (3). In Beijing/Xianghe, the correlation coefficients are similarly high between the different AMF versions, and slightly better for OMI than GOME2 (about 0.8 for GOME-2 and 0.9 for OMI). However, the slopes and offests of the regression lines between the satellite and ground-based observations show larger dependency on the AMF calculation settings. We find slopes of respectively $0.8,0.6$ and 0.9 for GOME-2 and 0.6, 0.6 and 1 for OMI. In Bujumbura, the number of ground-based measurements is unfortunately not large enough to draw conclusions about the correlations, and we rather provide the mean differences between the satellite and MAX-DOAS columns. The mean differences are found to be respectively $-2.8,-2.6$ and $1.1 \times 10^{15} \mathrm{molec} \mathrm{cm}^{-2}$ for GOME-2 and $-3.3,-2.6$ and $-0.9 \times 10^{15}$ molec cm $^{-2}$ for OMI. Results in China and in Burundi suggest that the cloud correction has little systematic influence, and therefore a limited effect on the monthly averaged columns, as indicated by the mean difference vari- 
Table 2. GOME-2A and OMI largest annual mean $\mathrm{H}_{2} \mathrm{CO}$ columns between 2007 and $2013\left(10^{15} \mathrm{molec}^{-2}\right)$.

\begin{tabular}{|c|c|c|c|c|c|c|}
\hline Continent & Country & Province/state & GOME-2A & seas.dev. & OMI & seas.dev. \\
\hline Africa & Congo & & 9.37 & 1.71 & 7.74 & 1.27 \\
\hline Africa & Ghana & & 8.97 & 2.79 & 8.47 & 2.6 \\
\hline Africa & Sierra Leone & & 10.26 & 3.76 & 9.21 & 3.95 \\
\hline Africa & Togo & & 8.96 & 2.77 & 8.49 & 2.62 \\
\hline Asia & Bangladesh & & 9.76 & 1.48 & 10.5 & 2.3 \\
\hline Asia & Cambodia & & 8.63 & 3.39 & 8.74 & 3.71 \\
\hline Asia & China & Anhui & 7.96 & 2.85 & 9.21 & 3.18 \\
\hline Asia & China & Guangdong & 8.59 & 1.44 & 9.82 & 1.34 \\
\hline Asia & China & Guangxi & 8.6 & 1.88 & 9.04 & 1.63 \\
\hline Asia & China & Hong Kong & 9.05 & 2.25 & 11.86 & 3.53 \\
\hline Asia & China & Jiangsu & 7.81 & 3.24 & 9.39 & 3.64 \\
\hline Asia & China & Tianjin & 7.8 & 4.75 & 9.86 & 3.84 \\
\hline Asia & India & Bihar & 9.67 & 1.44 & 10.5 & 2.01 \\
\hline Asia & India & Dadra and Nagar Haveli & 7.93 & 2.32 & 9.5 & 3.92 \\
\hline Asia & India & Daman and Diu & 8.35 & 2.5 & 9.27 & 4.31 \\
\hline Asia & India & Delhi & 10.2 & 2.85 & 12.2 & 2.91 \\
\hline Asia & India & Goa & 7.73 & 3.08 & 9.41 & 4.61 \\
\hline Asia & India & Haryana & 9.24 & 2 & 10.95 & 2.16 \\
\hline Asia & India & Kerala & 7.26 & 2.76 & 9.34 & 4.10 \\
\hline Asia & India & Orissa & 9.06 & 2.38 & 9.92 & 3.01 \\
\hline Asia & India & Punjab & 9.09 & 1.97 & 10.97 & 2.26 \\
\hline Asia & India & Tripura & 8.76 & 1.68 & 9.79 & 2.47 \\
\hline Asia & India & Uttar Pradesh & 8.79 & 1.58 & 10.2 & 1.69 \\
\hline Asia & India & West Bengal & 9.85 & 1.61 & 10.79 & 2.34 \\
\hline Asia & Singapore & & 9.14 & 2.79 & 8.9 & 3.62 \\
\hline Asia & Thailand & & 8.5 & 3.17 & 8.79 & 3.58 \\
\hline South America & Brazil & Mato Grosso & 11.19 & 4.23 & 8.72 & 3.82 \\
\hline South America & Brazil & Rondônia & 11.04 & 5.29 & 8.8 & 4.71 \\
\hline South America & Brazil & Tocantins & 10.55 & 2.66 & 8.62 & 2.57 \\
\hline South America & Bolivia & & 8.91 & 2.96 & 6.19 & 2.46 \\
\hline
\end{tabular}

Table 3. Summary of ground-based measurements available at BIRA-IASB.

\begin{tabular}{lllll}
\hline Station/country (lat, long) & Instrument & Period & Retrieved quantity & Reference \\
\hline $\begin{array}{l}\text { Cabauw/the Netherlands } \\
\left(52^{\circ} \mathrm{N}, 5^{\circ} \mathrm{E}\right)\end{array}$ & MAX-DOAS & 18 June 2009-21 July 2009 & VCD & Pinardi et al. (2013) \\
$\begin{array}{l}\text { Brussels/Belgium } \\
\left(50.78^{\circ} \mathrm{N}, 4.35^{\circ} \mathrm{E}\right)\end{array}$ & Mini-MAX-DOAS & 1 May 2011-23 April 2012 & VCD & Gielen et al. (2014) \\
$\begin{array}{l}\text { OHP/France } \\
\left(43.94^{\circ} \mathrm{N}, 5.71^{\circ} \mathrm{E}\right)\end{array}$ & MAX-DOAS & 26 July 2007-20 March 2013 & VCD & Valks et al. (2011) \\
$\begin{array}{l}\text { Beijing/China } \\
\left(39.98^{\circ} \mathrm{N}, 116.38^{\circ} \mathrm{E}\right)\end{array}$ & MAX-DOAS & 3 July 2008-17 April 2009 & VCD + profile & Vlemmix et al. (2014) \\
$\begin{array}{l}\text { Xianghe/China } \\
\left(39.75^{\circ} \mathrm{N}, 116.96^{\circ} \mathrm{E}\right)\end{array}$ & MAX-DOAS & 7 March 2010-26 December 2013 & VCD + profile & Vlemmix et al. (2014) \\
$\begin{array}{l}\text { Bujumbura/Burundi } \\
\left(3^{\circ} \mathrm{S}, 29^{\circ} \mathrm{E}\right)\end{array}$ & MAX-DOAS & 25 November 2013-22 April 2014 & VCD + profile & - \\
$\begin{array}{l}\text { Reunion/France } \\
\left(20.9^{\circ} \mathrm{S}, 55.5^{\circ} \mathrm{E}\right)\end{array}$ & FTIR & $\begin{array}{l}\text { 1 August 2004-25 October 2004 } \\
\text { 21 May 2007-15 October 2007 }\end{array}$ & VCD & Vigouroux et al. (2009) \\
& & 2 June 2009-28 December 2009 & &
\end{tabular}

ations between (1) and (2) (less than 10\%). On the contrary, the a priori vertical profile has a larger systematic effect on the vertical columns, as indicated by the different results between (2) and (3). Both for GOME-2 and OMI, switching from modelled to measured profile shapes increases the $\mathrm{H}_{2} \mathrm{CO}$ columns by 20 to $50 \%$, bringing the satellites and 
Table 4. Mean diurnal variations of the $\mathrm{H}_{2} \mathrm{CO}$ columns as observed with ground-based and satellite instruments. Values are given for five regions where BIRA-IASB operates ground-based measurements: Cabauw and Brussels, OHP, Beijing and Xianghe, and Bujumbura and Reunion. Details of the ground-based measurements are summarised in Table 3.

\begin{tabular}{llcccc}
\hline \multirow{2}{*}{ Station } & \multirow{2}{*}{ Instrument } & \multicolumn{3}{c}{ Absolute $13: 30-09: 30$ difference $\left(10^{14} \mathrm{molec} \mathrm{cm}^{-2}\right)$} \\
\cline { 3 - 6 } & & DJF & MAM & JJA & SON \\
\hline \multirow{2}{*}{ Cabauw, Brussels } & OMI-GOME-2 & - & $14 \pm 24$ & $25 \pm 27$ & $21 \pm 37$ \\
& MAX-DOAS & - & $12 \pm 25$ & $08 \pm 23$ & $20 \pm 21$ \\
\hline \multirow{2}{*}{ OHP } & OMI-GOME-2 & - & $30 \pm 27$ & $34 \pm 34$ & $29 \pm 34$ \\
& MAX-DOAS & $00 \pm 08$ & $09 \pm 10$ & $35 \pm 24$ & $18 \pm 14$ \\
\hline \multirow{2}{*}{ Beijing, Xianghe } & OMI-GOME-2 & - & $34 \pm 31$ & $39 \pm 67$ & $25 \pm 32$ \\
& MAX-DOAS & $-12 \pm 08$ & $-08 \pm 18$ & $44 \pm 40$ & $18 \pm 15$ \\
\hline \multirow{2}{*}{ Bujumbura } & OMI-GOME-2 & $-22 \pm 26$ & $-28 \pm 23$ & $-24 \pm 41$ & $-22 \pm 40$ \\
& MAX-DOAS & $-49 \pm 28$ & $-50 \pm 28$ & - & - \\
\hline \multirow{2}{*}{ Reunion } & OMI-GOME-2 & $14 \pm 22$ & $13 \pm 27$ & $16 \pm 18$ & $14 \pm 30$ \\
& FTIR & - & $13 \pm 20$ & $07 \pm 06$ & $06 \pm 09$ \\
\hline \multirow{2}{*}{} & & & & &
\end{tabular}

ground-based observations to a satisfactory agreement within $15 \%$. We note that the OMI columns in Beijing/Xianghe present a positive offset of about $3 \times 10^{15}$ molec $^{-2}$. The large effect of the a priori profile shape is explained by the vertical sensitivity of the satellite measurements, decreasing strongly in the lowest atmospheric layers, and by the shape of the $\mathrm{H}_{2} \mathrm{CO}$ vertical distribution, peaking near the surface. This is illustrated in Fig. 13, where the $\mathrm{H}_{2} \mathrm{CO}$ profile shapes modelled by IMAGES and those retrieved from the MAXDOAS measurements are plotted next to the satellite vertical sensitivity for June 2010 in Xianghe. It must be noted that the retrieved MAX-DOAS profiles also have their own uncertainties (Vlemmix et al., 2014); however, using them to re-calculate the satellite AMFs allows one to remove from the comparison the error associated with the a priori profile shapes (Eskes and Boersma, 2003). Indeed, only the shapes of the a priori profiles impact the satellite AMFs, not their total columns (Palmer et al., 2001). The satellite averaging kernels (AKs) are much closer in shape to the FTIR AKs than to the MAX-DOAS retrievals, which may explain the better agreement of the columns (Vigouroux et al., 2009).

The effect of the rather coarse resolution of the global CTM on the modelled profiles (here $2^{\circ} \times 2.5^{\circ}$ ) needs to be further investigated, particularly for anthropogenic sources, as well as other possible effects of vertical transport and chemical processes. For example, a recent analysis of in situ measurements in Beijing (Chen et al., 2014) indicated that primary sources of $\mathrm{H}_{2} \mathrm{CO}$ are responsible for as much as about $32 \%$ of the total $\mathrm{H}_{2} \mathrm{CO}$ source in the area, suggesting a strong underestimation of this direct source in current inventories. In the standard IMAGES simulation using the REASv2 inventory, this primary source contributes less than
$1 \%$ of the total $\mathrm{H}_{2} \mathrm{CO}$ source during the summer. Adjusting the primary source in the model to match the direct fraction estimated by Chen et al. (2014) results in the IMAGES profile shapes also shown in Fig. 13 (IMAGES prim1), found to agree much better with MAX-DOAS profiles. It is not clear whether this large apparent contribution of direct emissions is real or reflects e.g. a fast chemical production from highly reactive VOCs currently not well represented in inventories and models. Whatever the reasons might be for the improved model profiles in comparison with MAX-DOAS data, generalisation to other areas would appear premature. It is worth noting that the IMAGES model was found to reproduce very well observed vertical profiles of formaldehyde measured during aircraft campaigns over the United States and over oceans (Stavrakou et al., 2009c). More studies and measurements are required to refine our understanding of factors governing the formaldehyde vertical profiles.

\section{Long-term variations}

Formaldehyde columns are mainly formed by oxidation of NMVOCs from biogenic biomass burning and anthropogenic sources. Column inter-annual variabilities are mainly driven by fire events and temperature changes (Millet et al., 2008; Barkley et al., 2009; Stavrakou et al., 2014). However, over industrialised regions, changes in anthropogenic emissions have also been identified as drivers of observed $\mathrm{H}_{2} \mathrm{CO}$ column trends (De Smedt et al., 2010; Zhu et al., 2014; Khokhar et al., 2015; Mahajan et al., 2015; Stroud et al., 2015).

The TEMIS time series of morning $\mathrm{H}_{2} \mathrm{CO}$ columns, consisting of GOME, SCIAMACHY and GOME-2A and GOME-2B data, spans over 15 years of observations, while 

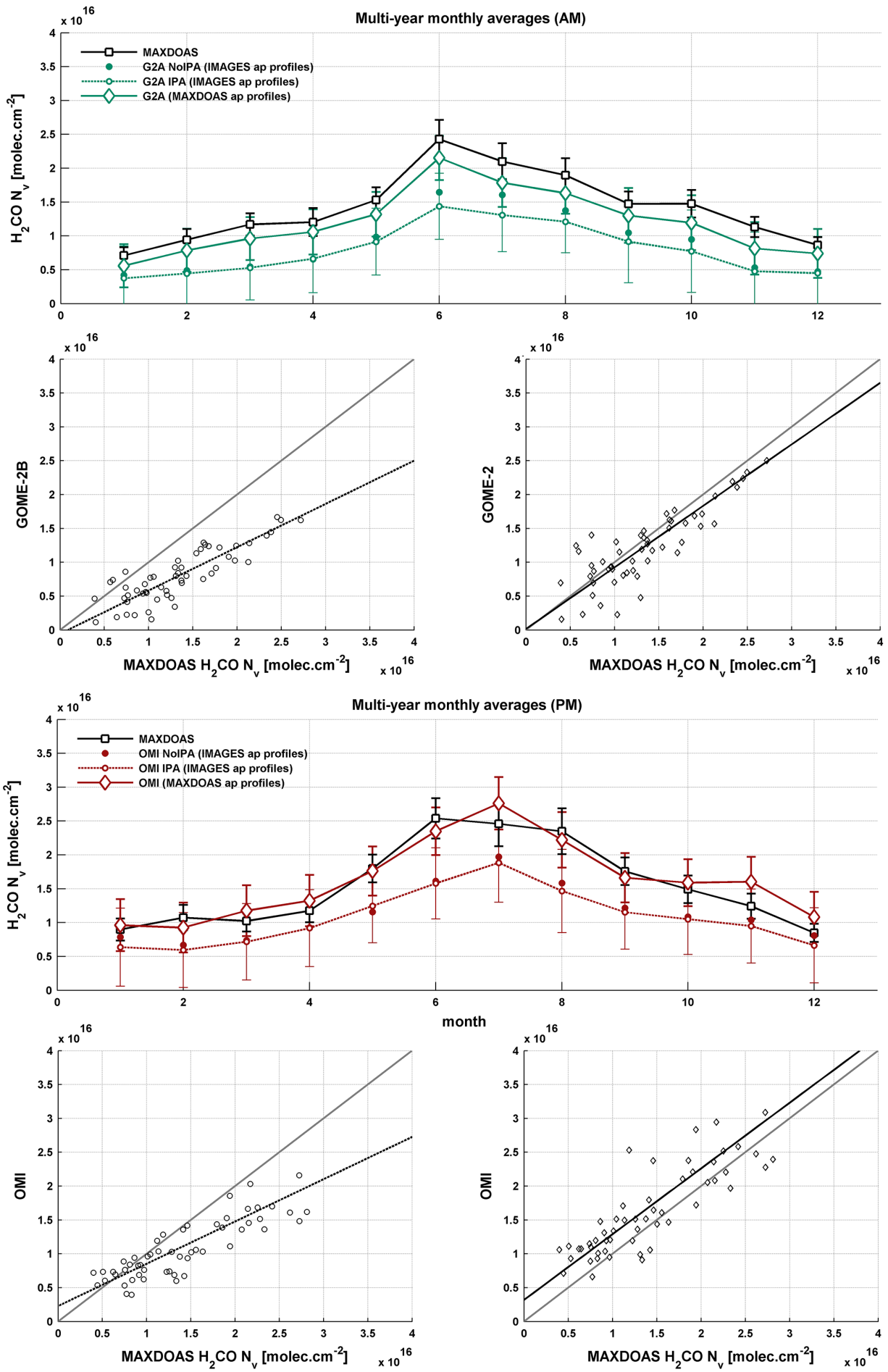

Figure 11. Validation of GOME-2 and OMI retrievals in Beijing and Xianghe, using MAX-DOAS retrievals (represented by black squares). Upper panel: mid-morning observations (GOME-2 and MAX-DOAS averaged over 8-11 h). Lower panel: early afternoon observations (OMI and MAX-DOAS averaged over 12-15 h). Observations have been averaged per month, over the period 2008-2013, selecting correlative days between GOME-2/OMI and the MAX-DOAS instrument. Satellite measurements have been averaged within $100 \mathrm{~km}$ around each location, and filtered using quality criteria as defined in Sect. 3.4. Three satellite VCs are presented: IMAGES a.p. profile/no cloud correction, IMAGES a.p. profile/IPA cloud correction, and MAX-DOAS a.p. profile/IPA cloud correction. Correlation plots are shown for the two latter cases, respectively, in the left and right panels. 

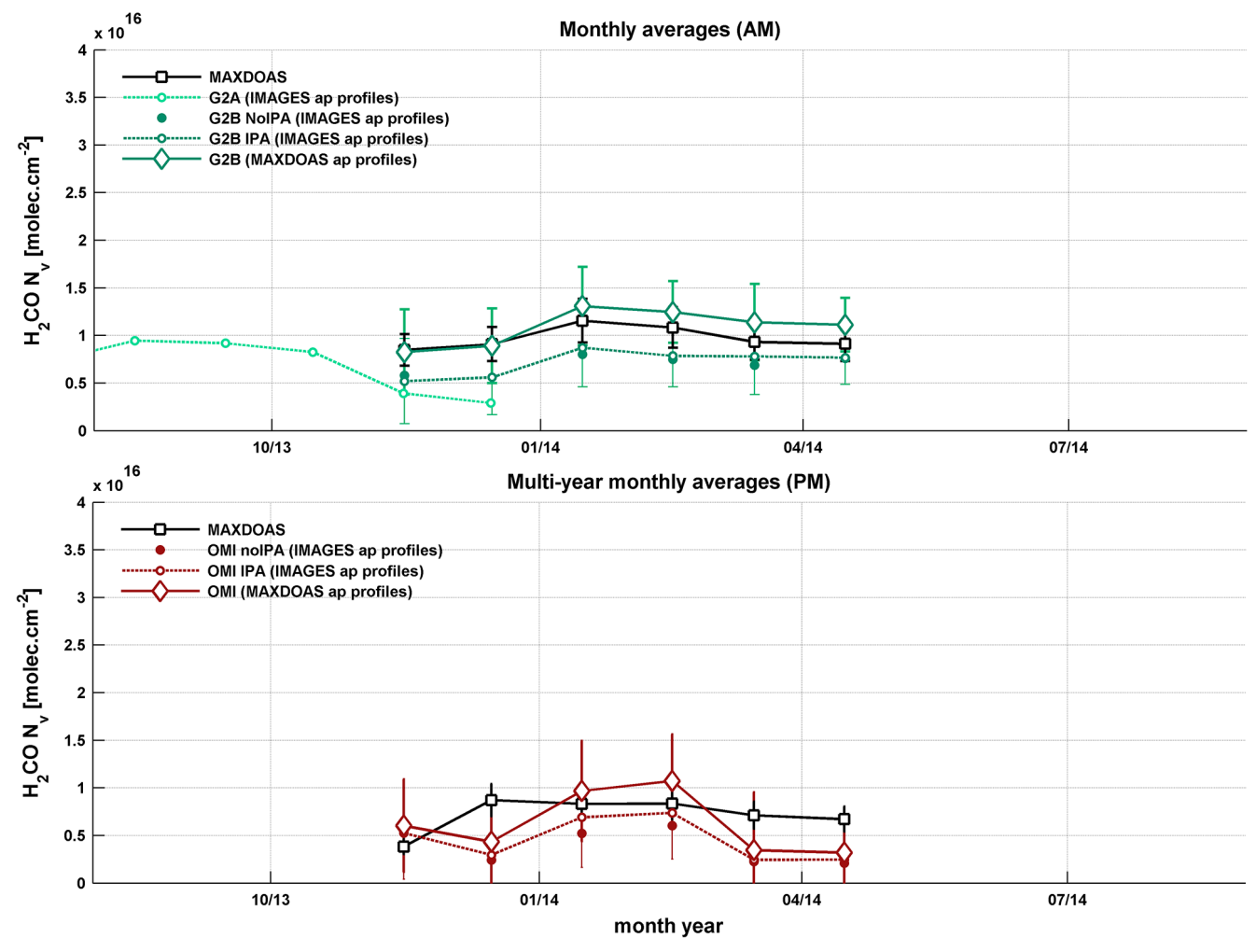

Figure 12. Validation of GOME-2 and OMI retrievals in Bujumbura, using MAX-DOAS retrievals (represented by black squares). Upper panel: mid-morning observations (GOME-2 AandB and MAX-DOAS averaged over 8-11 h). Lower panel: early afternoon observations (OMI and MAX-DOAS averaged over 12-15 h). Observations have been averaged per month, over the period 2013-2014, selecting correlative days between GOME-2/OMI and the MAX-DOAS instrument. Satellite measurements have been averaged within $100 \mathrm{~km}$ around each location, and filtered using quality criteria as defined in Sect. 3.4. Three GOME-2B and OMI VCs are presented: IMAGES a.p. profile/no cloud correction, IMAGES a.p. profile/IPA cloud correction, and MAX-DOAS a.p. profile/IPA cloud correction.

the afternoon time series derived from OMI covers 10 years of observations. Meaningful trend studies are therefore possible. We used a linear model with a seasonal component to fit the monthly averaged columns separately for the morning and afternoon time series. The error and statistical significance of the inferred trends are also estimated, as described in De Smedt et al. (2010). It is understood that the accuracy of such a trend analysis is limited in the case of $\mathrm{H}_{2} \mathrm{CO}$ because, like for the amplitude of the diurnal variation (between 1 and $4 \times 10^{15} \mathrm{molec}^{-2}$ ), the amplitude of the trends to be detected (about $1-2 \times 10^{15}$ molec cm$~^{-2}$ in 10 years) is 1 order of magnitude smaller than the $\mathrm{H}_{2} \mathrm{CO}$ columns, their errors and their seasonal variations. However, statistically significant trends are detected in several regions independently with both data sets, which gives confidence in our $\mathrm{H}_{2} \mathrm{CO}$ column long-term variation estimates.

Figures 14 to 16 present the time series of monthly averaged $\mathrm{H}_{2} \mathrm{CO}$ vertical columns in India, China, South America, Africa, North America and Europe. In those figures, the mid-morning time series (in green) combine SCIAMACHY (2003-2011), GOME-2A (2007-2013) and GOME-2B (from 2013) measurements, while early after- noon columns (in red) are derived from OMI measurements. The good agreement between the different morning observations can be noted (see also De Smedt et al., 2012), as well as the previously described differences and similarities between afternoon and morning time series. In particular, the higher morning columns over tropical forest are also observed in the SCIAMACHY time series. The results of our trend analysis are displayed whenever they have been found statistically significant, i.e. if the absolute value of the calculated trend is larger than twice the associated error. Furthermore, Fig. 17 presents a global map of the most significant trends found in the $\mathrm{OMI} \mathrm{H}_{2} \mathrm{CO}$ columns between November 2004 and $\mathrm{Au}-$ gust 2014. The analysis has been performed at country level on the global scale, at province or state level in the largest countries, and in a radius of $100 \mathrm{~km}$ around the main urban areas.

For these calculations, "sampling-corrected" OMI columns are used. Indeed, as shown in Fig. 6, the OMI daily spatial sampling has been reduced over the years because of the growing row anomaly. This has an impact on the $\mathrm{H}_{2} \mathrm{CO}$ monthly averaged columns, which tend to decrease in time if this effect is not taken into account. This decrease 


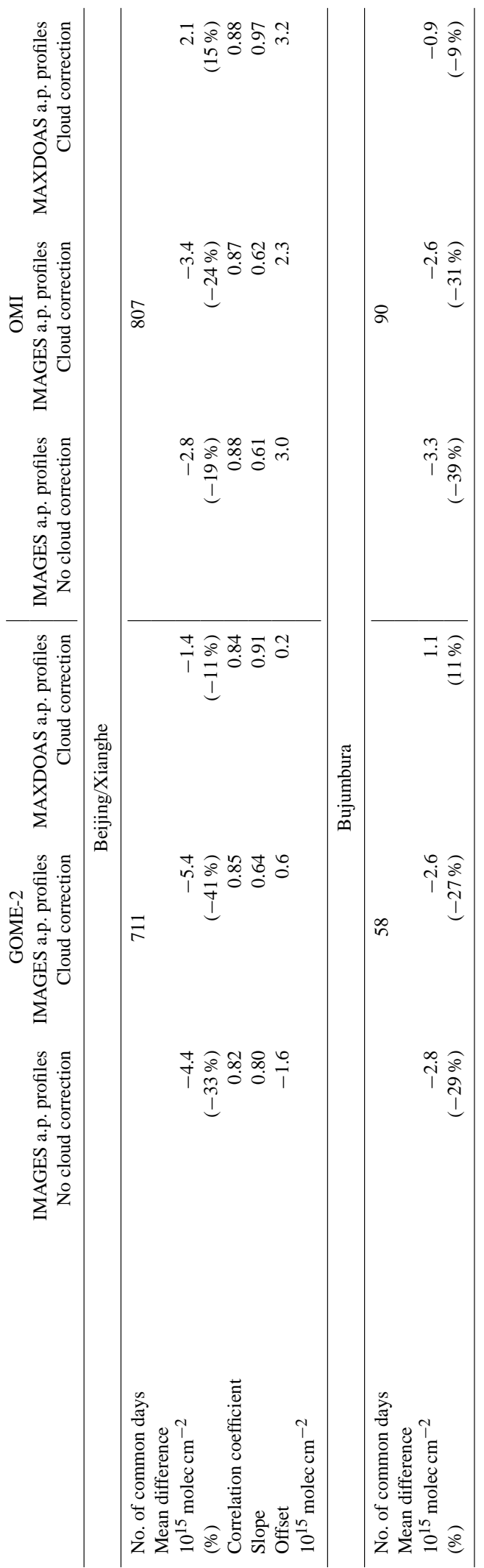

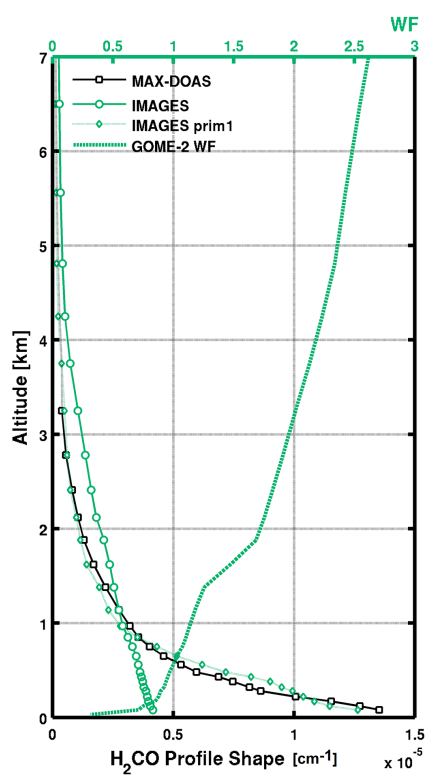

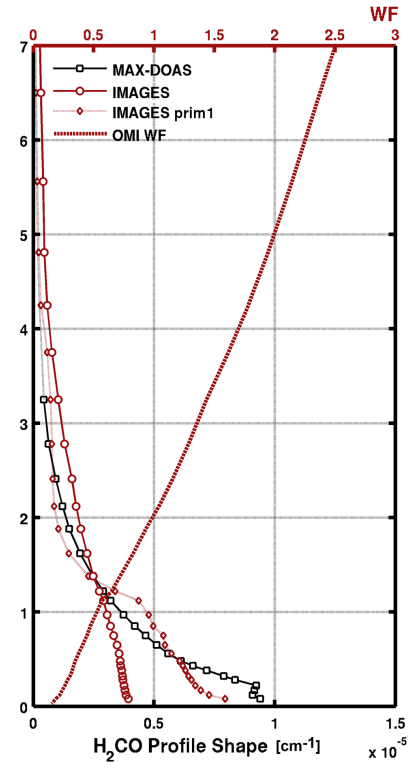

Figure 13. IMAGES CTM and MAX-DOAS retrieved $\mathrm{H}_{2} \mathrm{CO}$ profile shapes (concentration profiles divided by their total columns) averaged in June 2010 in Xianghe. IMAGES prim1 includes an additional primary source, as reported by Chen et al. (2014). The corresponding mean satellite scattering weighting functions are also displayed.

could be explained by the fact that a large number of central rows (rows 27-44 since January 2009), which have the finest spatial resolution, are affected by the anomaly and need to be filtered out. For this reason, we have calculated special OMI monthly averages, selecting only the rows that were still valid at the end of 2013. The net effect is a slight decrease of the columns at the beginning of the time series, almost negligible when looking at the absolute values, but significant when considering trends.

In India and China (Fig. 14), we observe increasing $\mathrm{H}_{2} \mathrm{CO}$ columns. The spatial distribution of the observed increases, and their values, is similar in the SCIAMACHY-GOME-2 and OMI time series. No trend is observed in the largest Chinese cities like Beijing and in the Pearl River delta. However, large positive trends are detected in the surrounding provinces, located in the centre of the country (e.g. Henan and Hunan provinces). This spatial shift of the Chinese trends outside the largest cities was already reported in De Smedt et al. (2010), using GOME and SCIAMACHY observations between 1997 and 2009. This might be related to a larger influence of newer, cleaner technologies in these mega-cities compared to the Chinese heartland (Zhang et al., 2009). In India, we observe positive trends almost everywhere, with an (absolute and relative) amplitude increasing from the south to north of the country. Values obtained from morning and afternoon observations are found to be consistent, and similar to the ones reported for the period 1997-2009. 

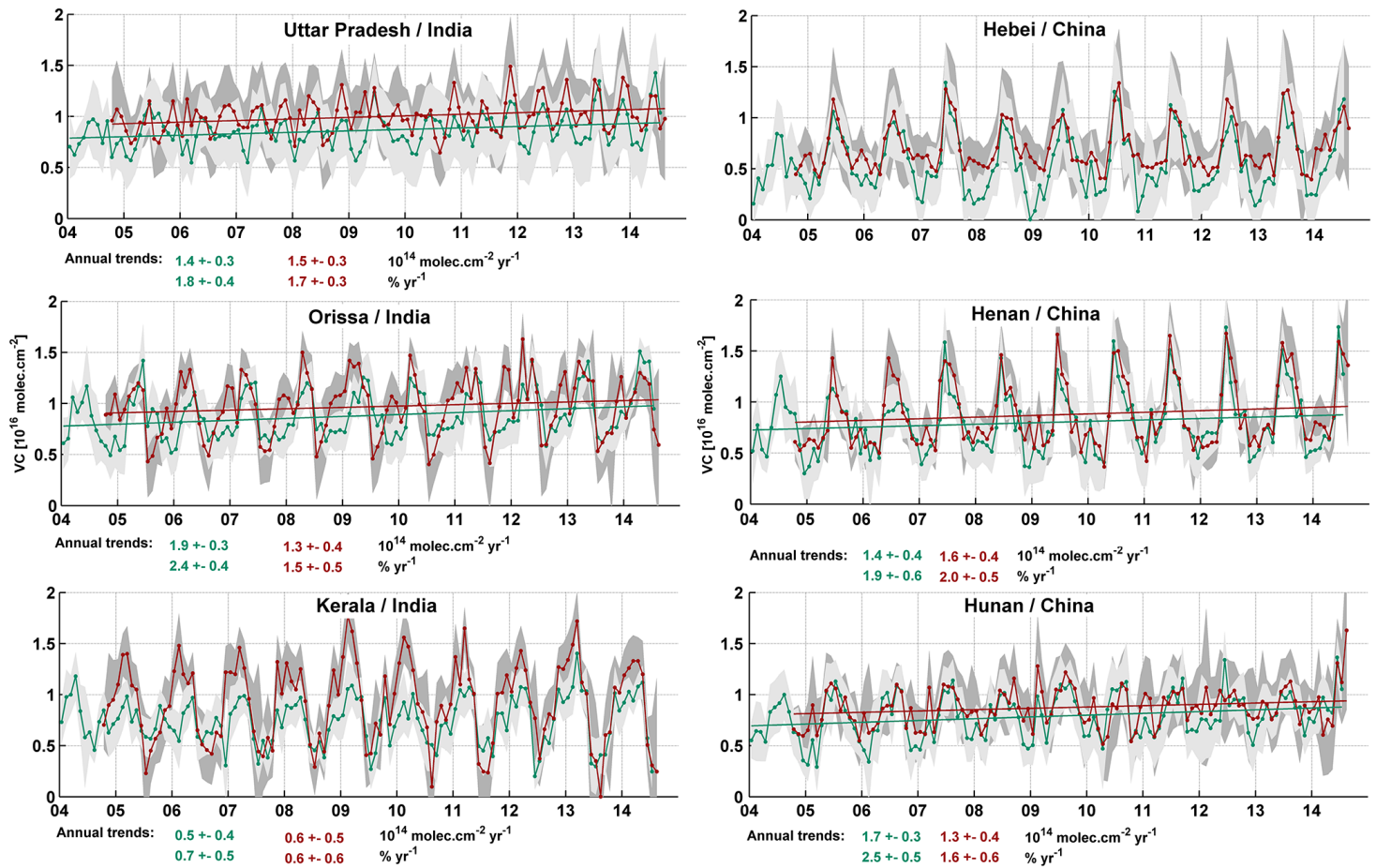

Figure 14. Monthly averaged $\mathrm{H}_{2} \mathrm{CO}$ vertical columns as observed from satellite instruments in India and China. Mid-morning columns (in green) consist of SCIAMACHY (2003-2011) and GOME-2A (2007-2013) and GOME-2B (2013- ) measurements. If statistically significant, results of the trend analysis are displayed (De Smedt et al., 2010).
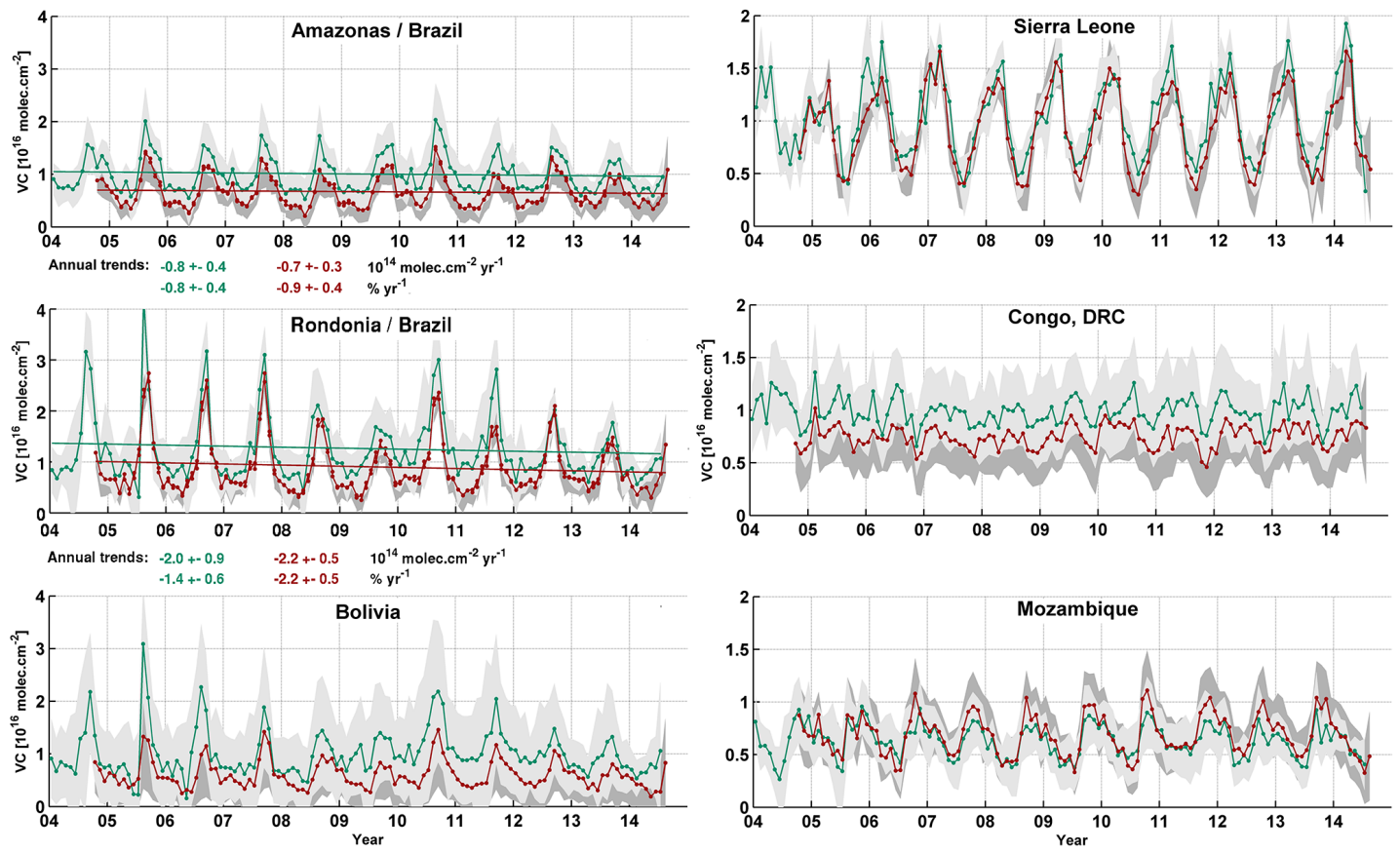

Figure 15. Monthly averaged $\mathrm{H}_{2} \mathrm{CO}$ vertical columns as observed from satellite instruments in South America and Africa. Mid-morning columns (in green) consist of SCIAMACHY (2003-2011), GOME-2A (2007-2013) and GOME-2B (2013- ) measurements, while early afternoon columns (in red) are derived from OMI measurements. If statistically significant, results of the trend analysis are displayed (De Smedt et al., 2010). 

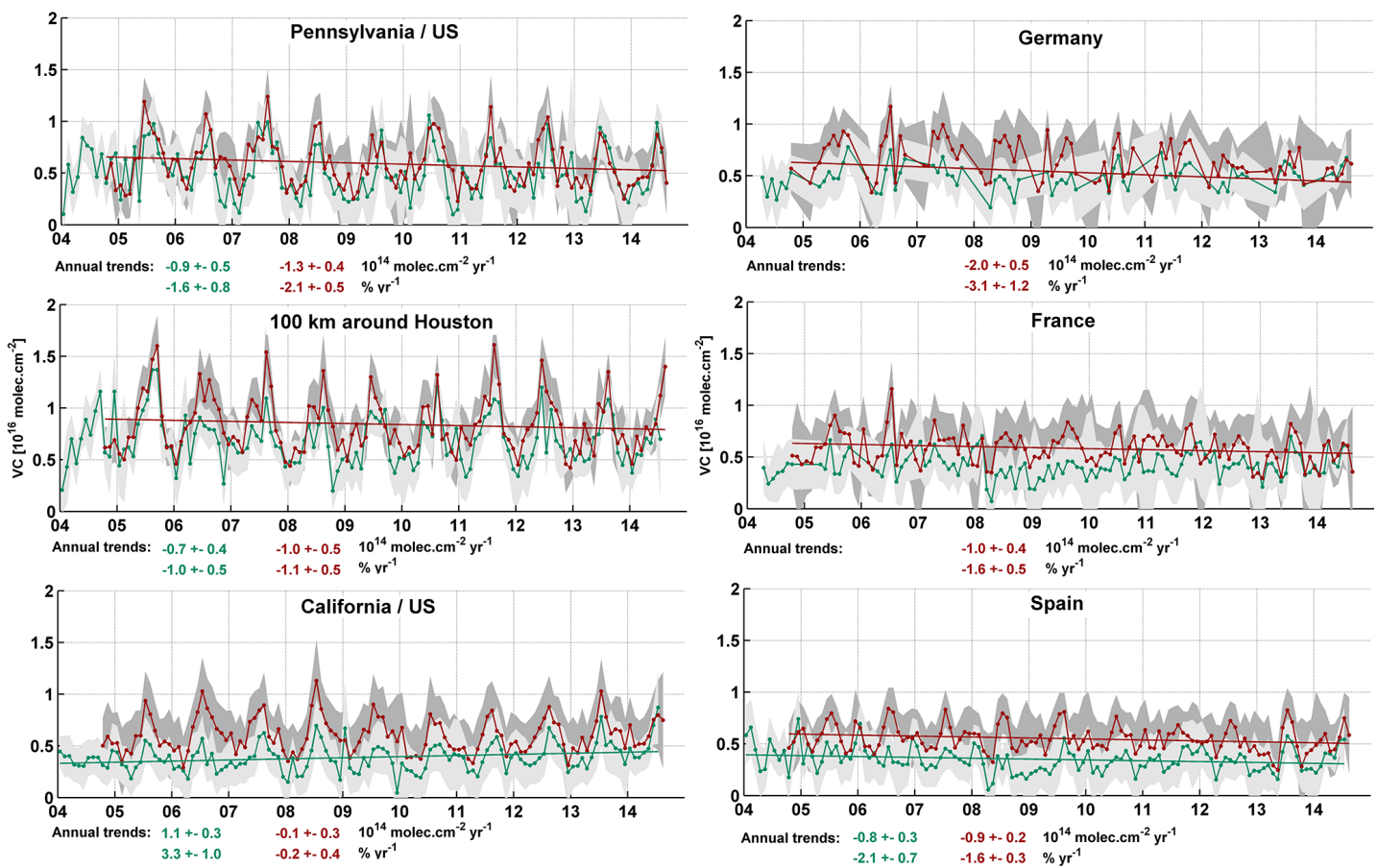

Figure 16. Monthly averaged $\mathrm{H}_{2} \mathrm{CO}$ vertical columns as observed from satellite instruments in US and Europe. Mid-morning columns (in green) consist of SCIAMACHY (2003-2011) and GOME-2A (2007-2013) and GOME-2B (2013- ) measurements, while early afternoon columns (in red) are derived from OMI measurements. If statistically significant, results of the trend analysis are displayed (De Smedt et al., 2010).

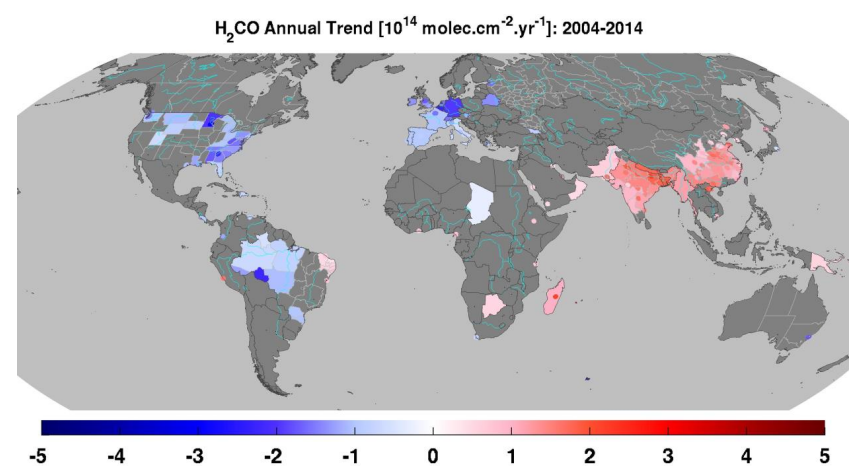

Figure 17. Annual absolute trends observed in the $\mathrm{OMI} \mathrm{H}_{2} \mathrm{CO}$ columns between November 2004 and August 2014. The change in the OMI spatial sampling over the years has been taken into account in this trend analysis.

In the eastern US and western Europe (Fig. 16), we observe decreasing trends more clearly detected in the OMI retrievals. The morning $\mathrm{H}_{2} \mathrm{CO}$ observations have larger errors and the wintertime observations cannot be used. Negative trends have previously been reported, but with less statistical significance (De Smedt et al., 2010). Here, the correlation between the SCIAMACHY/GOME-2 and OMI observations is found to be good even in these retrieval-sensitive regions, giving some new confidence in the morning time se- ries over northern Europe and North America. The expected negative trends due to emission controls are better captured by the early afternoon observations of OMI, allowing the detection of significant decreases in Germany and France. In southern European countries like Spain, negative trends can be detected in both time series, which show remarkable correlation, with for example very low values in spring 2008 that could be related to power plant emission reductions as reported for $\mathrm{NO}_{2}$ by Curier et al. (2014).

Over the African continent (right panels of Fig. 15), almost no change is detected, with the exception of Madagascar, and its capital Antananarivo, where a large positive trend is found in the OMI time series. The origin of this trend is not understood for the moment. No similar increase has been reported in satellite $\mathrm{NO}_{2}$ observations over this region (see for example Hilboll et al., 2013). In South America (left panels of Fig. 15), we observe very significant negative trends over the Brazilian state of Rondônia, of $-2 \times 10^{14} \mathrm{molec}^{-2} \mathrm{yr}^{-1}$, in both morning and afternoon time series. Such negative trends are also present, with lower amplitudes, in the surrounding Brazilian states covered by the Amazon forest. The largest $\mathrm{H}_{2} \mathrm{CO}$ columns worldwide are observed in those regions, with very large variations between the dry and the wet season (see Table 2). Figure 18 shows the $\mathrm{H}_{2} \mathrm{CO}$ columns in Rondônia between 2003 and 2014, the MODIS (on Terra and Aqua satellites) Collection 5 Active Fire Prod- 

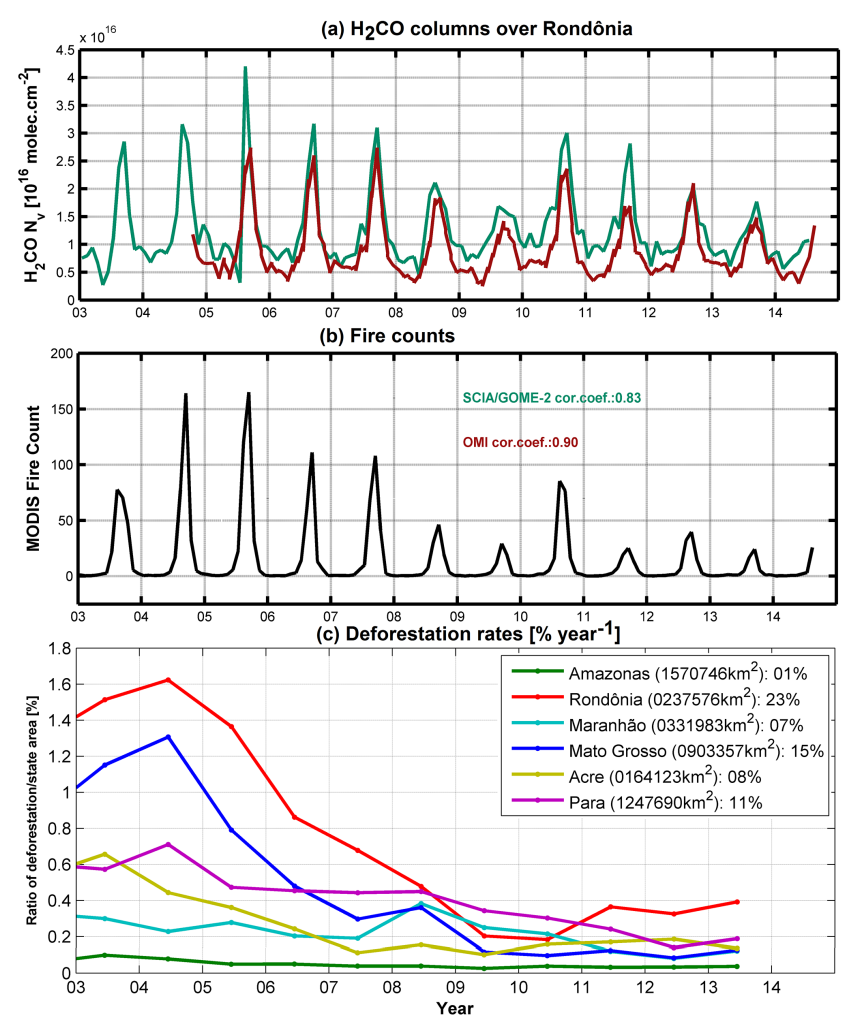

Figure 18. (a) Monthly averaged $\mathrm{H}_{2} \mathrm{CO}$ vertical columns from SCIAMACHY/GOME2 (in green) and from OMI (in red) (first panel) and (b) MODIS fire count (second panel) over the Rondônia Brazilian state. Inset values are the correlation coefficient between the satellite $\mathrm{H}_{2} \mathrm{CO}$ columns and the fire counts. (c) Reported yearly deforestation rates in selected Brazilian states, relative to their respective surfaces (third panel; source: Brazil INPE). Inset values are the total surface of the state and the total rate of deforestation between 1988 and 2013.

uct (ftp://fuoco.geog.umd.edu/modis/C5/cmg, Giglio, 2013), and the yearly deforestation rates reported by the Brazilian INPE (http://www.obt.inpe.br/prodes/index.php), in selected Amazonian states. Deforestation in Rondônia amounted to $23 \%$ of its surface area between 1988 and 2013. This is the highest surface ratio among all Brazilian states. The years showing the highest deforestation rates are 1995 and 2004. In Rondônia, a strong decrease of the deforestation rate has been observed between 2005 and 2010, and a slight increase is again observed since 2011. As illustrated by the middle panel of Fig. 18, we find high correlation coefficients between the SCIAMACHY/GOME- 2 and $\mathrm{OMI}_{2} \mathrm{CO}$ columns and the MODIS fire product, of respectively 0.8 and 0.9 (see also Barkley et al., 2013). We have also compared the $\mathrm{H}_{2} \mathrm{CO}$ vertical columns with GISS surface temperature anomalies (Gridded Monthly Maps of Temperature Anomaly Data, http://data.giss.nasa.gov/gistemp/; Hansen et al., 2010), but no correlation was found in this area. Vegetation burning related to deforestation appears to have strongly decreased in Rondônia, while it is not yet the case in the surrounding areas. It should be noted that the strong enhancement of natural fire emissions during very dry years (such as 2005 and 2010) somehow reduces the observed downward trend in the fires and $\mathrm{H}_{2} \mathrm{CO}$ columns, and therefore the correlation with the reported deforestation rates.

Besides these direct effects of biomass burning activity changes on the $\mathrm{H}_{2} \mathrm{CO}$ columns, more studies are needed in order to assess the impact of deforestation and land use changes, and possibly related meteorological changes, on biogenic NMVOC emissions (Stavrakou et al., 2014). It is worth noting that BIRA-IASB is currently installing a FTIR instrument in Porto Velho, in the Rondônia state. This will bring new information on both the diurnal cycle of $\mathrm{H}_{2} \mathrm{CO}$ columns and its chemistry, and more generally, on the carbon cycle molecules $\left(\mathrm{CO}_{2}, \mathrm{CH}_{4}, \mathrm{CO}\right.$ and NMVOCs).

\section{Conclusions}

This paper presents a new version of the BIRA-IASB formaldehyde retrieval algorithm that has been applied to the complete time series of OMI and GOME-2 measurements and delivered for public use on the TEMIS website. Our focus is the continuity and the consistency of the $\mathrm{H}_{2} \mathrm{CO}$ data set, as well as a good characterisation of the satellite observations. The spectral fits have been improved by means of a better treatment of the interference between $\mathrm{O}_{4}, \mathrm{BrO}$ and $\mathrm{H}_{2} \mathrm{CO}$ differential structures, resulting in $\mathrm{H}_{2} \mathrm{CO}$ columns of higher accuracy and precision. Daily remote radiance spectra are used as DOAS reference, and a destriping procedure is included in the background sector correction, reducing the impact of the OMI row anomaly, but also the GOME-2 across-track variability. Daily morning and afternoon a priori profiles are provided by a state-of-the-art version of the IMAGES global CTM.

The GOME- 2 and OMI $\mathrm{H}_{2} \mathrm{CO}$ data sets agree very well qualitatively, in terms of both long-term variations and seasonal variations. Vertical columns also agree reasonably well, although systematic differences are observed, depending on the geographical location. The morning $\mathrm{H}_{2} \mathrm{CO}$ observations are higher than the afternoon observations over tropical rainforests of the Amazon basin, Africa, and Indonesia. The OMI observations are larger than the GOME- 2 columns over urban areas (pointing to a horizontal resolution effect) and more generally over all mid-latitude regions (pointing to a combination of actual diurnal variation effects and differences in retrieval sensitivities between morning and afternoon observations).

A detailed validation study has been performed using correlative ground-based MAX-DOAS measurements in Belgium/Netherlands, southern France, north-eastern China, Burundi and FTIR measurements in Reunion. We show that the differences observed between the GOME- 2 and OMI $\mathrm{H}_{2} \mathrm{CO}$ columns are mainly consistent with the diurnal varia- 
tions observed from the ground, within the error bars of the satellite and ground-based observations. In Beijing/Xianghe and Bujumbura, MAX-DOAS vertical profiles have been used to re-calculate the satellite air mass factors, allowing one to eliminate from the comparison the error coming from the a priori profiles. By doing so, the satellite and MAXDOAS columns are found to agree to within $15 \%$ or better.

To conclude, while the precision is driven by the signalto-noise ratio of the recorded spectra, the accuracy is limited by our current knowledge of the external parameters needed for the retrieval, mainly the a priori profile shapes and their diurnal variation and the cloud and aerosol properties. To fully exploit the potential of satellite data, scientific studies relying on tropospheric $\mathrm{H}_{2} \mathrm{CO}$ observations require consistently retrieved long-term time series, provided with wellcharacterised errors and averaging kernels. In the framework of prototype algorithm developments for the future TROPOMI instrument to be flown on the ESA Copernicus Sentinel-5 Precursor mission, we are currently investigating the impact of using global CTM profiles on a finer horizontal resolution. Verification and validation studies are ongoing with the aim of further improving the retrieval algorithms. Furthermore, in the context of the EU QA4ECV project (www.qa4ecv.eu/), a $\mathrm{H}_{2} \mathrm{CO}$ climate data record (CDR) using all the satellite instruments based on a jointly optimised European algorithm is currently under development.

Acknowledgements. The $\mathrm{H}_{2} \mathrm{CO}$ data products from GOME-2 were generated at BIRA using level-1 data developed by EUMETSAT. Level-2 and level-3 $\mathrm{H}_{2} \mathrm{CO}$ scientific products from GOME-2 have been jointly supported by Belgian PRODEX (A3C and TRACES5P), ESA (PROMOTE) and EU (AMFIC). BIRA is also involved in the O3MSAF (CDOP-2 project), where it supports the development and validation of the GOME- $2 \mathrm{H}_{2} \mathrm{CO}$ operational product generated at DLR. The $\mathrm{H}_{2} \mathrm{CO}$ data products from OMI were generated at BIRA using level-1 data developed at NASA/KNMI. Level-2 and level-3 OMI $\mathrm{H}_{2} \mathrm{CO}$ developments are supported as part of the Sentinel-5 precursor TROPOMI level-2 project, funded by ESA and Belgian PRODEX (TRACE-S5P project). Multi-sensor $\mathrm{H}_{2} \mathrm{CO}$ developments at BIRA are currently supported by EU FP7 (QA4ECV project), in cooperation with KNMI, the University of Bremen and MPIC-Mainz. Modelling at BIRA was funded by the Belgian PRODEX projects $\mathrm{A} 3 \mathrm{C}$ and ACROSAT. MAX-DOAS measurements were funded by Belgian Federal Science Policy Office, Brussels (AGACC-II project), the EU 7th Framework Programme projects NORS and ACTRIS, and the ESA CEOS Intercalibration project. Acknowledgements are addressed to the Université de La Réunion and CNRS (LACy-UMR8105 and UMS3365) for their support of the OPAR station and the OSU-R activities.

Edited by: T. von Clarmann

\section{References}

Alvarado, L. M. A., Richter, A., Vrekoussis, M., Wittrock, F., Hilboll, A., Schreier, S. F., and Burrows, J. P.: An improved glyoxal retrieval from OMI measurements, Atmos. Meas. Tech., 7, 4133-4150, doi:10.5194/amt-7-4133-2014, 2014.

Barkley, M. P., Palmer, P. I., Ganzeveld, L. N., Arneth, A., Hagberg, D., Karl, T., Guenther, A. B., Paulot, F., Wennberg, P. O., Mao, J., Kurosu, T. P., Chance, K., Müller, J. F., De Smedt, I., Van Roozendael, M., Chen, D., Wang, Y., and Yantosca, R. M.: Can a "state of the art" chemistry transport model simulate Amazonian tropospheric chemistry?, J. Geophys. Res., 116, D16302, doi:10.1029/2011JD015893, 2011.

Barkley, M. P., De Smedt, I., Van Roozendael, M., Kurosu, T. P., Chance, K. V., Arneth, A., Hagberg, D., Guenther, A. B., Paulot, F., Marais, E. A., and Mao, J.: Top-down isoprene emissions over tropical South America inferred from SCIAMACHY and OMI formaldehyde columns, J. Geophys. Res. Atmos., 118, 120, doi:10.1002/jgrd.50552, 2013.

Begoin, M., Richter, A., Weber, M., Kaleschke, L., Tian-Kunze, X., Stohl, A., Theys, N., and Burrows, J. P.: Satellite observations of long range transport of a large $\mathrm{BrO}$ plume in the Arctic, Atmos. Chem. Phys., 10, 6515-6526, doi:10.5194/acp-10-65152010, 2010.

Boersma, K. F., Eskes, H. J., Dirksen, R. J., van der A, R. J., Veefkind, J. P., Stammes, P., Huijnen, V., Kleipool, Q. L., Sneep, M., Claas, J., Leitão, J., Richter, A., Zhou, Y., and Brunner, D.: An improved tropospheric $\mathrm{NO}_{2}$ column retrieval algorithm for the Ozone Monitoring Instrument, Atmos. Meas. Tech., 4, 19051928, doi:10.5194/amt-4-1905-2011, 2011.

Brion, J., Chakir, A., Charbonnier, J., Daumont, D., Parisse, C., and Malicet, J.: Absorption spectra measurements for the ozone molecule in the 350-830 nm region, J. Atmos. Chem., 30, 291299, 1998.

Callies, J., Corpaccioli, E., Eisinger, M., Hahne, A., and Lefebvre, A.: GOME-2- Metop's second-generation sensor for operational ozone monitoring, ESA Bull., 102, 28-36, 2000.

Castellanos, P., Boersma, K. F., Torres, O., and de Haan, J. F.: OMI tropospheric $\mathrm{NO}_{2}$ air mass factors over South America: effects of biomass burning aerosols, Atmos. Meas. Tech., 8, 3831-3849, doi:10.5194/amt-8-3831-2015, 2015.

Chance, K. and Kurucz, R. L.: An improved high-resolution solar reference spectrum for earth's atmosphere measurements in the ultraviolet, visible, and near infrared, J. Quant. Spectrosc. Ra., 111, 1289-1295, 2010.

Chance, K., Palmer, P. I., Spurr, R. J., Martin, R. V., Kurosu, T. P., and Jacob D. J.: Satellite observations of formaldehyde over North America from GOME, Geophys. Res. Lett., 27, 34613464, 2000.

Chan Miller, C., Gonzalez Abad, G., Wang, H., Liu, X., Kurosu, T., Jacob, D. J., and Chance, K.: Glyoxal retrieval from the Ozone Monitoring Instrument, Atmos. Meas. Tech., 7, 38913907, doi:10.5194/amt-7-3891-2014, 2014.

Chen, W. T., Shao, M., Lu, S. H., Wang, M., Zeng, L. M., Yuan, B., and Liu, Y.: Understanding primary and secondary sources of ambient carbonyl compounds in Beijing using the PMF model, Atmos. Chem. Phys., 14, 3047-3062, doi:10.5194/acp-14-30472014, 2014.

Choi, S., Wang, Y., Salawitch, R. J., Canty, T., Joiner, J., Zeng, T., Kurosu, T. P., Chance, K., Richter, A., Huey, L. G., Liao, J., Neu- 
man, J. A., Nowak, J. B., Dibb, J. E., Weinheimer, A. J., Diskin, G., Ryerson, T. B., da Silva, A., Curry, J., Kinnison, D., Tilmes, S., and Levelt, P. F.: Analysis of satellite-derived Arctic tropospheric $\mathrm{BrO}$ columns in conjunction with aircraft measurements during ARCTAS and ARCPAC, Atmos. Chem. Phys., 12, 12551285, doi:10.5194/acp-12-1255-2012, 2012.

Clémer, K., Van Roozendael, M., Fayt, C., Hendrick, F., Hermans, C., Pinardi, G., Spurr, R., Wang, P., and De Mazière, M.: Multiple wavelength retrieval of tropospheric aerosol optical properties from MAXDOAS measurements in Beijing, Atmos. Meas. Tech., 3, 863-878, doi:10.5194/amt-3-863-2010, 2010.

Curci, G., Palmer, P. I., Kurosu, T. P., Chance, K., and Visconti, G.: Estimating European volatile organic compound emissions using satellite observations of formaldehyde from the Ozone Monitoring Instrument, Atmos. Chem. Phys., 10, 11501-11517, doi:10.5194/acp-10-11501-2010, 2010.

Curier, L., Kranenburg, R., Segers, A. J. S., Timmermans, R. M. A., and Schaap, M.: Synergistic use of $\mathrm{OMI} \mathrm{NO}_{2}$ tropospheric columns and LOTOS-EUROS to evaluate the $\mathrm{NO}_{x}$ emission trends across Europe, Remote Sens. Environ., 149, 58-69, doi:10.1016/j.rse.2014.03.032, 2014.

Danckaert, T., Fayt, C., Van Roozendael, M., De Smedt, I., Letocart, V., Merlaud, A., and Pinardi, G.: Qdoas Software User Manual, Version 2.108, available at: http://uv-vis.aeronomie.be/software/ QDOAS/index.php (last access: 30 October 2015), 2014.

Daumont, M., Brion, J., Charbonnier, J., and Malicet, J.: Ozone UV spectroscopy, I: Absorption cross-sections at room temperature, J. Atmos. Chem., 15, 145-155, 1992.

De Smedt, I., Müller, J.-F., Stavrakou, T., van der A, R., Eskes, H., and Van Roozendael, M.: Twelve years of global observations of formaldehyde in the troposphere using GOME and SCIAMACHY sensors, Atmos. Chem. Phys., 8, 4947-4963, doi:10.5194/acp-8-4947-2008, 2008.

De Smedt, I., Stavrakou, T., Müller, J. F., van Der A, R. J., and Van Roozendael, M.: Trend detection in satellite observations of formaldehyde tropospheric columns, Geophys. Res. Lett., 37, L18808, doi:10.1029/2010GL044245, 2010.

De Smedt, I.: Long-Term Global Observations of Tropospheric Formaldehyde Retrieved from Spaceborne Nadir UV Sensors, $\mathrm{PhD}$ thesis, Universite Libre De Bruxelles, Laboratoire de Chimie Quantique et Photophysique, Faculté de Sciences Appliquées, 2011.

De Smedt, I., Van Roozendael, M., Stavrakou, T., Müller, J.-F., Lerot, C., Theys, N., Valks, P., Hao, N., and van der A, R.: Improved retrieval of global tropospheric formaldehyde columns from GOME-2/MetOp-A addressing noise reduction and instrumental degradation issues, Atmos. Meas. Tech., 5, 2933-2949, doi:10.5194/amt-5-2933-2012, 2012.

De Smedt, I., Van Roozendael, M., Danckaert, T., Van Gent, J., Theys, N., and Lerot, C.: TROPOMI/S5P ATBD of Formaldehyde data product, S5P- BIRA-L2-400F- ATBD, 2014.

Dikty, S. and Richter, A.: GOME-2 on MetOp-A Support for Analysis of GOME-2 In-Orbit Degradation and Impacts on Level 2 Data Products, Final Report, Version 1.2, 14 October 2011.

Dobber, M., Dirksen, R. P. F., Levelt, P., van den Oord, G. H. J., Voors, R. H. M., Kleipool, Q., Jaross, G., Kowalewski, M., Hilsenrath, E., Leppelmeier, G., de Vries, J., Dierssen, W., and Rozemeijer, N.: Ozone Monitoring Instrument Cali- bration, IEEE Trans. Geosci. Remote Sens., 44, 1209-1238, doi:10.1109/TGRS.2006.869987, 2006.

Dobber, M., Kleipool, Q., Dirksen, R., Levelt, P., Jaross, G., Taylor, S., Kelly, T., Flynn, L., Leppelmeier, G., and Rozemeijer, N.: Validation of Ozone Monitoring Instrument level $1 \mathrm{~b}$ data products, J. Geophys. Res., 113, D15S06, doi:10.1029/2007JD008665, 2008.

Eskes, H. J. and Boersma, K. F.: Averaging kernels for DOAS totalcolumn satellite retrievals, Atmos. Chem. Phys., 3, 1285-1291, doi:10.5194/acp-3-1285-2003, 2003.

Fleischmann, O. C., Hartmann, M., Burrows, J. P., and Orphal, J.: New ultraviolet absorption cross-sections of $\mathrm{BrO}$ at atmospheric temperatures measured by time-windowing Fourier transform spectroscopy, J. Photochem. Photobiol. A, 168, 117-132, 2004.

Fortems-Cheiney, A., Chevallier, F., Pison, I., Bousquet, P., Saunois, M., Szopa, S., Cressot, C., Kurosu, T. P., Chance, K., and Fried, A.: The formaldehyde budget as seen by a global-scale multiconstraint and multi-species inversion system, Atmos. Chem. Phys., 12, 6699-6721, doi:10.5194/acp-12-6699-2012, 2012.

Fu, T.-M., Jacob, D. J., Palmer, P. I., Chance, K. V., Wang, Y. X., Barletta, B., Blake, D. R., Stanton, J. C., and Pilling, M. J.: Space-based formaldehyde measurements as constraints on volatile organic compound emissions in east and south Asia and implications for ozone, J. Geophys. Res., 112, D06312, doi:10.1029/2006JD007853, 2007.

Gielen, C., Van Roozendael, M., Hendrick, F., Pinardi, G., Vlemmix, T., De Bock, V., De Backer, H., Fayt, C., Hermans, C., Gillotay, D., and Wang, P.: A simple and versatile cloudscreening method for MAX-DOAS retrievals, Atmos. Meas. Tech., 7, 3509-3527, doi:10.5194/amt-7-3509-2014, 2014.

Giglio, L., Randerson, J. T., and van der Werf, G. R.: Analysis of daily, monthly, and annual burned area using the fourthgeneration global fire emissions database (GFED4), J. Geophys. Res.-Biogeosci., 118, 317-328, doi:10.1002/jgrg.20042, 2013.

Gomez, L., Navarro-Comas, M., Puentedura, O., Gonzalez, Y., Cuevas, E., and Gil-Ojeda, M.: Long-path averaged mixing ratios of $\mathrm{O}_{3}$ and $\mathrm{NO}_{2}$ in the free troposphere from mountain MAXDOAS, Atmos. Meas. Tech., 7, 3373-3386, doi:10.5194/amt-73373-2014, 2014.

González Abad, G., Liu, X., Chance, K., Wang, H., Kurosu, T. P., and Suleiman, R.: Updated Smithsonian Astrophysical Observatory Ozone Monitoring Instrument (SAO OMI) formaldehyde retrieval, Atmos. Meas. Tech., 8, 19-32, doi:10.5194/amt-8-192015, 2015a.

González Abad, G., Vasilkov, A., Seftor, C., Liu, X., and Chance, K.: Smithsonian Astrophysical Observatory Ozone Mapping and Profiler Suite (SAO OMPS) formaldehyde retrieval, Atmos. Meas. Tech. Discuss., 8, 9209-9240, doi:10.5194/amtd-8-92092015, 2015b.

Hansen, J., Ruedy, R., Sato, M., and Lo, K.: Global surface temperature change, Rev. Geophys., 48, RG4004, doi:10.1029/2010RG000345, 2010.

Heckel, A., Richter, A., Tarsu, T., Wittrock, F., Hak, C., Pundt, I., Junkermann, W., and Burrows, J. P.: MAX-DOAS measurements of formaldehyde in the Po-Valley, Atmos. Chem. Phys., 5, 909918, doi:10.5194/acp-5-909-2005, 2005.

Hendrick, F., Müller, J.-F., Clémer, K., Wang, P., De Mazière, M., Fayt, C., Gielen, C., Hermans, C., Ma, J. Z., Pinardi, G., Stavrakou, T., Vlemmix, T., and Van Roozendael, M.: Four years of ground-based MAX-DOAS observations of HONO and 
$\mathrm{NO}_{2}$ in the Beijing area, Atmos. Chem. Phys., 14, 765-781, doi:10.5194/acp-14-765-2014, 2014.

Hewson, W., Bösch, H., Barkley, M. P., and De Smedt, I.: Characterisation of GOME-2 formaldehyde retrieval sensitivity, Atmos. Meas. Tech., 6, 371-386, doi:10.5194/amt-6-371-2013, 2013.

Hilboll, A., Richter, A., and Burrows, J. P.: Long-term changes of tropospheric $\mathrm{NO}_{2}$ over megacities derived from multiple satellite instruments, Atmos. Chem. Phys., 13, 4145-4169, doi:10.5194/acp-13-4145-2013, 2013.

Ingmann, P., Veihelmann, B., Langen, J., Lamarre, D., Stark, H., and Courrèges-Lacoste, G. B.: Requirements for the GMES Atmosphere Service and ESA's implementation concept: Sentinels-4/-5 and -5p, Remote Sens. Environ., 120, 58-69, doi:10.1016/j.rse.2012.01.023, 2012.

Irie, H., Takashima, H., Kanaya, Y., Boersma, K. F., Gast, L., Wittrock, F., Brunner, D., Zhou, Y., and Van Roozendael, M.: Eightcomponent retrievals from ground-based MAX-DOAS observations, Atmos. Meas. Tech., 4, 1027-1044, doi:10.5194/amt-41027-2011, 2011.

Khokhar, M. F., Khalid, T., Yasmin, N. and De Smedt, I.: SpatioTemporal Analyses of Formaldehyde over Pakistan by Using SCIAMACHY and GOME-2 Observations, Aerosol Air Qual. Res., 15, 1-14, doi:10.4209/aaqr.2014.12.0339, 2015.

Kleipool, Q. L., Dobber, M. R., de Haan, J. F., and Levelt, P. F.: Earth surface reflectance climatology from 3 years of OMI data, J. Geophys. Res., 113, D18308, doi:10.1029/2008JD010290, 2008.

Kurokawa, J., Ohara, T., Morikawa, T., Hanayama, S., JanssensMaenhout, G., Fukui, T., Kawashima, K., and Akimoto, H.: Emissions of air pollutants and greenhouse gases over Asian regions during 2000-2008: Regional Emission inventory in ASia (REAS) version 2, Atmos. Chem. Phys., 13, 11019-11058, doi:10.5194/acp-13-11019-2013, 2013.

Kurosu, T. P.: OMHCHO README FILE, available at: https://www.cfa.harvard.edu/atmosphere/Instruments/OMI/ PGEReleases/READMEs/OMHCHO_README.pdf (last access: 22 April 2015), 2008

Leitão, J., Richter, A., Vrekoussis, M., Kokhanovsky, A., Zhang, Q. J., Beekmann, M., and Burrows, J. P.: On the improvement of $\mathrm{NO}_{2}$ satellite retrievals - aerosol impact on the airmass factors, Atmos. Meas. Tech., 3, 475-493, doi:10.5194/amt-3-475-2010, 2010.

Lerot, C., Stavrakou, T., De Smedt, I., Müller, J.-F., and Van Roozendael, M.: Glyoxal vertical columns from GOME-2 backscattered light measurements and comparisons with a global model, Atmos. Chem. Phys., 10, 12059-12072, doi:10.5194/acp10-12059-2010, 2010.

Levelt, P. F., van den Oord, G. H., Dobber, M. R., Malkki, A., Visser, H., de Vries, J., Stammes, P., Lundell, J. O., and Saari, H.: The ozone monitoring instrument, IEEE Trans. Geosci. Remote Sens., 44, 1093-1101, 2006.

Li, C., Joiner, J., Krotkov, N. A., and Dunlap, L.: A new method for global retrievals of HCHO total columns from the Suomi National Polar-orbiting Partnership Ozone Mapping and Profiler Suite, Geophys. Res. Lett., 42, 2515-2522, doi:10.1002/2015GL063204, 2015.

Ma, J. Z., Beirle, S., Jin, J. L., Shaiganfar, R., Yan, P., and Wagner, T.: Tropospheric $\mathrm{NO}_{2}$ vertical column densities over Beijing: results of the first three years of ground-based MAX-DOAS mea- surements (2008-2011) and satellite validation, Atmos. Chem. Phys., 13, 1547-1567, doi:10.5194/acp-13-1547-2013, 2013.

Mahajan, A. S., De Smedt, I., Biswas, M. S., Ghude, S., Fadnavis, S., Roy, C., and van Roozendael, M.: Inter-annual variations in satellite observations of nitrogen dioxide and formaldehyde over India, Atmos. Environ., 116, 194-201, doi:10.1016/j.atmosenv.2015.06.004, 2015.

Malicet, C., Daumont, D., Charbonnier, J., Parisse, C., Chakir, A., and Brion, J.: Ozone UV spectroscopy, II: Absorption crosssections and temperature dependence, J. Atmos. Chem., 21, 263 273, 1995.

Marais, E. A., Jacob, D. J., Kurosu, T. P., Chance, K., Murphy, J. G., Reeves, C., Mills, G., Casadio, S., Millet, D. B., Barkley, M. P., Paulot, F., and Mao, J.: Isoprene emissions in Africa inferred from OMI observations of formaldehyde columns, Atmos. Chem. Phys., 12, 6219-6235, doi:10.5194/acp-12-62192012, 2012.

Martin, R. V., Chance, K. V., Jacob, D. J., Kurosu, T. P., Spurr, R. J. D., Bucsela, E. J., Gleason, J., Palmer, P. I., Bey, I., Fiore, A. M., Li, Q., Yantosca, R. M., and Koelemeijer, R. B. A.: An improved retrieval of tropospheric nitrogen dioxide from GOME, J. Geophys. Res., 107, 4437, doi:10.1029/2001JD001027, 2002.

Meller, R. and Moortgat, G. K.: Temperature dependence of the absorption cross section of $\mathrm{HCHO}$ between 223 and $323 \mathrm{~K}$ in the wavelength range 225-375 nm, J. Geophys. Res., 105, 70897102, doi:10.1029/1999JD901074, 2000.

Millet, D. B., Jacob, D. J., Boersma, K. F., Fu, T.-M., Kurosu, T. P., Chance, K. V., Heald, C. L., and Guenther, A.: Spatial distribution of isoprene emissions from North America derived from formaldehyde column measurements by the OMI satellite sensor, J. Geophys. Res., 113, 1-18, doi:10.1029/2007JD008950, 2008.

Munro, R., Eisinger, M., Anderson, C., Callies, J., Corpaccioli, E., Lang, R., Lefebvre, A., Livschitz, Y., and Albinana, A. P.: GOME-2 on MetOp, Proc. of The 2006 EUMETSAT Meteorological Satellite Conference, Helsinki, Finland, 2006.

Palmer, P. I., Jacob, D. J., Chance, K. V., Martin, R. V. D. R. J., Kurosu, T. P., Bey, I., Yantosca, R. M., and Fiore, A. M.: Air mass factor formulation for spectroscopic measurements from satellites: Application to formaldehyde retrievals from the Global Ozone Monitoring Experiment, J. Geophys. Res., 106, 1453914550, doi:10.1029/2000JD900772, 2001.

Palmer, P. I., Abbot, D. S., Fu, T.-M., Jacob, D. J., Chance, K. V., Kurosu, T. P., Guenther, A., Wiedinmyer, C., Stanton, J. C., Pilling, M. J., Pressley, S. N., Lamb, B., and Sumner, A. L.: Quantifying the seasonal and interannual variability of North American isoprene emissions using satellite observations of the formaldehyde column, J. Geophys. Res., 111, 1-14, doi:10.1029/2005JD006689, 2006.

Pinardi, G., Van Roozendael, M., Abuhassan, N., Adams, C., Cede, A., Clémer, K., Fayt, C., Frieß, U., Gil, M., Herman, J., Hermans, C., Hendrick, F., Irie, H., Merlaud, A., Navarro Comas, M., Peters, E., Piters, A. J. M., Puentedura, O., Richter, A., Schönhardt, A., Shaiganfar, R., Spinei, E., Strong, K., Takashima, H., Vrekoussis, M., Wagner, T., Wittrock, F., and Yilmaz, S.: MAXDOAS formaldehyde slant column measurements during CINDI: intercomparison and analysis improvement, Atmos. Meas. Tech., 6, 167-185, doi:10.5194/amt-6-167-2013, 2013.

Puksīe, J., Kühl, S., Deutschmann, T., Platt, U., and Wagner, T.: Extending differential optical absorption spectroscopy for limb 
measurements in the UV, Atmos. Meas. Tech., 3, 631-653, doi:10.5194/amt-3-631-2010, 2010.

Richter, A., Begoin, M., Hilboll, A., and Burrows, J. P.: An improved $\mathrm{NO}_{2}$ retrieval for the GOME-2 satellite instrument, Atmos. Meas. Tech., 4, 1147-1159, doi:10.5194/amt-4-1147-2011, 2011.

Salawitch, R. J., Canty, T., Kurosu, T., et al.: A new interpretation of total column BrO during Arctic spring, Geophys. Res. Lett., 37, L21805, doi:10.1029/2010GL043798, 2010.

Sander, S. P., Abbatt, J., Barker, J. R., Burkholder, J. B., Friedl, R. R., Golden, D. M., Huie, R. E., Kolb, C. E., Kurylo, M. J., Moortgat, G. K., Orkin, V. L., and Wine, P. H.: Chemical Kinetics and Photochemical Data for Use in Atmospheric Studies, Evaluation No. 17, JPL Publication 10-6, Jet Propulsion Laboratory, Pasadena, 1320, 2011.

Schultz, M. G., Heil, A., Hoelzemann, J. J., Spessa, A., Thonicke, K., Goldammer, J. G., Held, A. C., Pereira, J. M. C., and van het Bolscher, M.: Global wildland fire emissions from 1960 to 2000, Global Biogeochem. Cy., 22, GB2002, doi:10.1029/2007GB003031, 2008.

Stammes, P., Sneep, M., de Haan, J. F., Veefkind, J. P., Wang, P., and Levelt, P. F.: Effective cloud fractions from the Ozone Monitoring Instrument: Theoretical framework and validation, J. Geophys. Res., 113, D16S38, doi:10.1029/2007JD008820, 2008.

Stavrakou, T., Müller, J.-F., De Smedt, I., Van Roozendael, M., van der Werf, G. R., Giglio, L., and Guenther, A.: Global emissions of non-methane hydrocarbons deduced from SCIAMACHY formaldehyde columns through 2003-2006, Atmos. Chem. Phys., 9, 3663-3679, doi:10.5194/acp-9-3663-2009, 2009a.

Stavrakou, T., Müller, J.-F., De Smedt, I., Van Roozendael, M., Kanakidou, M., Vrekoussis, M., Wittrock, F., Richter, A., and Burrows, J. P.: The continental source of glyoxal estimated by the synergistic use of spaceborne measurements and inverse modelling, Atmos. Chem. Phys., 9, 8431-8446, doi:10.5194/acp-98431-2009, 2009b.

Stavrakou, T., Müller, J.-F., De Smedt, I., Van Roozendael, M., van der Werf, G. R., Giglio, L., and Guenther, A.: Evaluating the performance of pyrogenic and biogenic emission inventories against one decade of space-based formaldehyde columns, Atmos. Chem. Phys., 9, 1037-1060, doi:10.5194/acp-9-1037-2009, 2009c.

Stavrakou, T., Müller, J.-F., Boersma, K. F., van der A, R. J., Kurokawa, J., Ohara, T., and Zhang, Q.: Key chemical $\mathrm{NO}_{x}$ sink uncertainties and how they influence top-down emissions of nitrogen oxides, Atmos. Chem. Phys., 13, 9057-9082, doi:10.5194/acp-13-9057-2013, 2013.

Stavrakou, T., Müller, J.-F., Bauwens, M., De Smedt, I., Van Roozendael, M., Guenther, A., Wild, M., and Xia, X.: Isoprene emissions over Asia 1979-2012: impact of climate and land-use changes, Atmos. Chem. Phys., 14, 4587-4605, doi:10.5194/acp14-4587-2014, 2014.

Stroud, C. A., Zaganescu, C., Chen, J., McLinden, C. A., Zhang, J., and Wang, D.: Toxic volatile organic air pollutants across Canada: multi-year concentration trends, regional air quality modelling and source apportionment, J. Atmos. Chem., 1-28, doi:10.1007/s10874-015-9319-z, 2015.

Spurr, R. J. D.: LIDORT and VLIDORT: Linearized pseudospherical scalar and vector discrete ordinate radiative transfer models for use in remote sensing retrieval problems, in Light
Scattering Reviews, edited by: Kokhanovsky, A., Berlin, 229271, 2008.

Thalman, R. and Volkamer, R.: Temperature dependent absorption cross-sections of O2-O2 collision pairs between 340 and $630 \mathrm{~nm}$ and at atmospherically relevant pressure, Phys. Chem. Chem. Phys., 15, 15371-15381, doi:10.1039/c3cp50968k, 2013.

Theys, N., Van Roozendael, M., Hendrick, F., Yang, X., De Smedt, I., Richter, A., Begoin, M., Errera, Q., Johnston, P. V., Kreher, K., and De Mazière, M.: Global observations of tropospheric BrO columns using GOME-2 satellite data, Atmos. Chem. Phys., 11, 1791-1811, doi:10.5194/acp-11-1791-2011, 2011.

Theys, N., De Smedt, I., van Gent, J., Danckaert, T., Wang, T., Hendrick, F., Stavrakou, T., Bauduin, S., Clarisse, L., Li, C., Krotkov, N., Yu, H., Brenot, H., and Van Roozendael, M.: Sulfur dioxide vertical column DOAS retrievals from the Ozone Monitoring Instrument: Global observations and comparison to ground-based and satellite data, J. Geophys. Res. Atmos., 120, 2014JD022657, doi:10.1002/2014JD022657, 2015.

Valks, P., Pinardi, G., Richter, A., Lambert, J.-C., Hao, N., Loyola, D., Van Roozendael, M., and Emmadi, S.: Operational total and tropospheric $\mathrm{NO}_{2}$ column retrieval for GOME-2, Atmos. Meas. Tech., 4, 1491-1514, doi:10.5194/amt-4-1491-2011, 2011.

Vandaele, A. C., Hermans, C., Fally, S., Carleer, M., Colin, R., Mérienne, M.-F., Jenouvrier, A., and Coquart, B.: Highresolution Fourier transform measurement of the $\mathrm{NO}_{2}$ visible and near-infrared absorption cross-section: Temperature and pressure effects, J. Geophys. Res., 107, 4348, doi:10.1029/2001JD000971, 2002.

van der Werf, G. R., Randerson, J. T., Giglio, L., Collatz, G. J., Mu, M., Kasibhatla, P. S., Morton, D. C., DeFries, R. S., Jin, Y., and van Leeuwen, T. T.: Global fire emissions and the contribution of deforestation, savanna, forest, agricultural, and peat fires (19972009), Atmos. Chem. Phys., 10, 11707-11735, doi:10.5194/acp10-11707-2010, 2010.

Veefkind, J. P., Aben, I., McMullan, K., Förster, H., de Vries, J., Otter, G., Claas, J., Eskes, H. J., de Haan, J. F., Kleipool, Q., van Weele, M., Hasekamp, O., Hoogeveen, R., Landgraf, J., Snel, R., Tol, P., Ingmann, P., Voors, R., Kruizinga, B., Vink, R., Visser, H., and Levelt, P.: TROPOMI on the ESA Sentinel-5 Precursor: A GMES mission for global observations of the atmospheric composition for climate, air quality and ozone layer applications, Remote Sens. Environ., 120, 70-83, doi:10.1016/j.rse.2011.09.027, 2012.

Vigouroux, C., Hendrick, F., Stavrakou, T., Dils, B., De Smedt, I., Hermans, C., Merlaud, A., Scolas, F., Senten, C., Vanhaelewyn, G., Fally, S., Carleer, M., Metzger, J.-M., Müller, J.-F., Van Roozendael, M., and De Mazière, M.: Ground-based FTIR and MAX-DOAS observations of formaldehyde at Réunion Island and comparisons with satellite and model data, Atmos. Chem. Phys., 9, 9523-9544, doi:10.5194/acp-9-9523-2009, 2009.

Vlemmix, T., Hendrick, F., Pinardi, G., Smedt, I., De Fayt, C., Hermans, C., Piters, A., Wang, P., and Levelt, P.: MAX-DOAS observations of aerosols, formaldehyde and nitrogen dioxide in the Beijing area: comparison of two profile retrieval, Atmos. Meas. Tech., 2, 941-963, doi:10.5194/amt-8-941-2015, 2015.

Vountas, M., Rozanov, V. V., and Burrows, J. P.: Ring effect: impact of rotational Raman scattering on radiative transfer in earth's atmosphere, J. Quant. Spectrosc. Ra., 60, 943-961, 1998. 
Vrekoussis, M., Wittrock, F., Richter, A., and Burrows, J. P.: GOME-2 observations of oxygenated VOCs: what can we learn from the ratio glyoxal to formaldehyde on a global scale?, Atmos. Chem. Phys., 10, 10145-10160, doi:10.5194/acp-1010145-2010, 2010.

Wang, P., Stammes, P., van der A, R., Pinardi, G., and van Roozendael, M.: FRESCO+: an improved $\mathrm{O}_{2}$ A-band cloud retrieval algorithm for tropospheric trace gas retrievals, Atmos. Chem. Phys., 8, 6565-6576, doi:10.5194/acp-8-6565-2008, 2008.

Wang, T., Hendrick, F., Wang, P., Tang, G., Clémer, K., Yu, H., Fayt, C., Hermans, C., Gielen, C., Müller, J.-F., Pinardi, G., Theys, N., Brenot, H., and Van Roozendael, M.: Evaluation of tropospheric $\mathrm{SO}_{2}$ retrieved from MAX-DOAS measurements in Xianghe, China, Atmos. Chem. Phys., 14, 11149-11164, doi:10.5194/acp14-11149-2014, 2014.
Wittrock, F., Richter, A., Oetjen, H., Burrows, J. P., Kanakidou, M., Myriokefalitakis, S., Volkamer, R., Beirle, S., Platt, U., and Wagner, T.: Simultaneous global observations of glyoxal and formaldehyde from space, Geophys. Res. Lett., 33, L16804, doi:10.1029/2006GL026310, 2006.

Zhang, Q., Streets, D. G., Carmichael, G. R., He, K. B., Huo, H., Kannari, A., Klimont, Z., Park, I. S., Reddy, S., Fu, J. S., Chen, D., Duan, L., Lei, Y., Wang, L. T., and Yao, Z. L.: Asian emissions in 2006 for the NASA INTEX-B mission, Atmos. Chem. Phys., 9, 5131-5153, doi:10.5194/acp-9-5131-2009, 2009.

Zhu, L., Jacob, D. J., Mickley, L. J., Marais, E. A., Cohan, D. S., Yoshida, Y., Duncan, B. N., González Abad, G., and Chance, K. V.: Anthropogenic emissions of highly reactive volatile organic compounds in eastern Texas inferred from oversampling of satellite (OMI) measurements of HCHO columns, Environ. Res. Lett., 9, 114004, doi:10.1088/1748-9326/9/11/114004, 2014. 